BNL-52433

(Rev. 12/94)

\title{
ADVANCED NEUTRON SOURCE ENRICHMENT STUDY
}

\section{Volume 1: Main Report}

Prepared by: R.A. Bari, H. Ludewig, and J. Weeks

DEPARTMENT OF ADVANCED TECHNOLOGY

BROOKHAVEN NATIONAL LABORATORY

UPTON, NEW YORK 11973

Prepared for: U.S. DEPARTMENT OF ENERGY

December 31, 1994

Final Report

This work was performed under the auspices of the U.S. Department of Energy, under Contract No. DE-ACO2-76CH00016. 


\section{DISCLAIMER}

This report was prepared as an account of work sponsored by an agency of the United States Government. Neither the United States Government nor any agency thereof, nor any of their employees, nor any of their contractors, subcontractors, or their employees, makes any warranty, express or implied, or assumes any legal liability or responsibility for the accuracy, completeness, or usefulness of any information, apparatus, product, or process disclosed, or represents that its use would not infringe privately owned rights. Reference herein to any specific commercial product, process, or service by trade name, trademark, manufacturer, or otherwise, does not necessarily constitute or imply its endorsement, recommendation, or favoring by the United States Government or any agency, contractor or subcontractor thereof. The views and opinions of authors expressed herein do not necessarily state or reflect those of the United States Government or any agency, contractor or subcontractor thereof.

\section{Printed in the United States of America}

Available from

National Technical Information Service

U.S. Department of Commerce

5285 Port Royal Road

Springfield, VA 22161

NTIS price codes:

Printed Copy: A05; Microfiche Copy: A01 


\section{DISCLAIMER}

Portions of this document may be illegible in electronic image products. Images are produced from the best available original document. 


\begin{abstract}
A study has been performed of the impact on performance of using low enriched uranium $\left(20 \%{ }^{235} \mathrm{U}\right)$ or medium enriched uranium $\left(35 \%{ }^{235} \mathrm{U}\right)$ as an alternative fuel for the Advanced Neutron Source, which is currently designed to use uranium enriched to $93 \%{ }^{235} \mathrm{U}$. Higher fuel densities and larger volume cores were evaluated at the lower enrichments in terms of impact on neutron flux, safety, safeguards, technical feasibility, and cost. The feasibility of fabricating uranium silicide fuel at increasing material density was specifically addressed by a panel of international experts on research reactor fuels. The most viable alternative designs for the reactor at lower enrichments were identified and discussed. Several sensitivity analyses were performed to gain an understanding of the performance of the reactor at parametric values of power, fuel density, core volume, and enrichment that were interpolations between the boundary values imposed on the study or extrapolations from known technology.
\end{abstract}




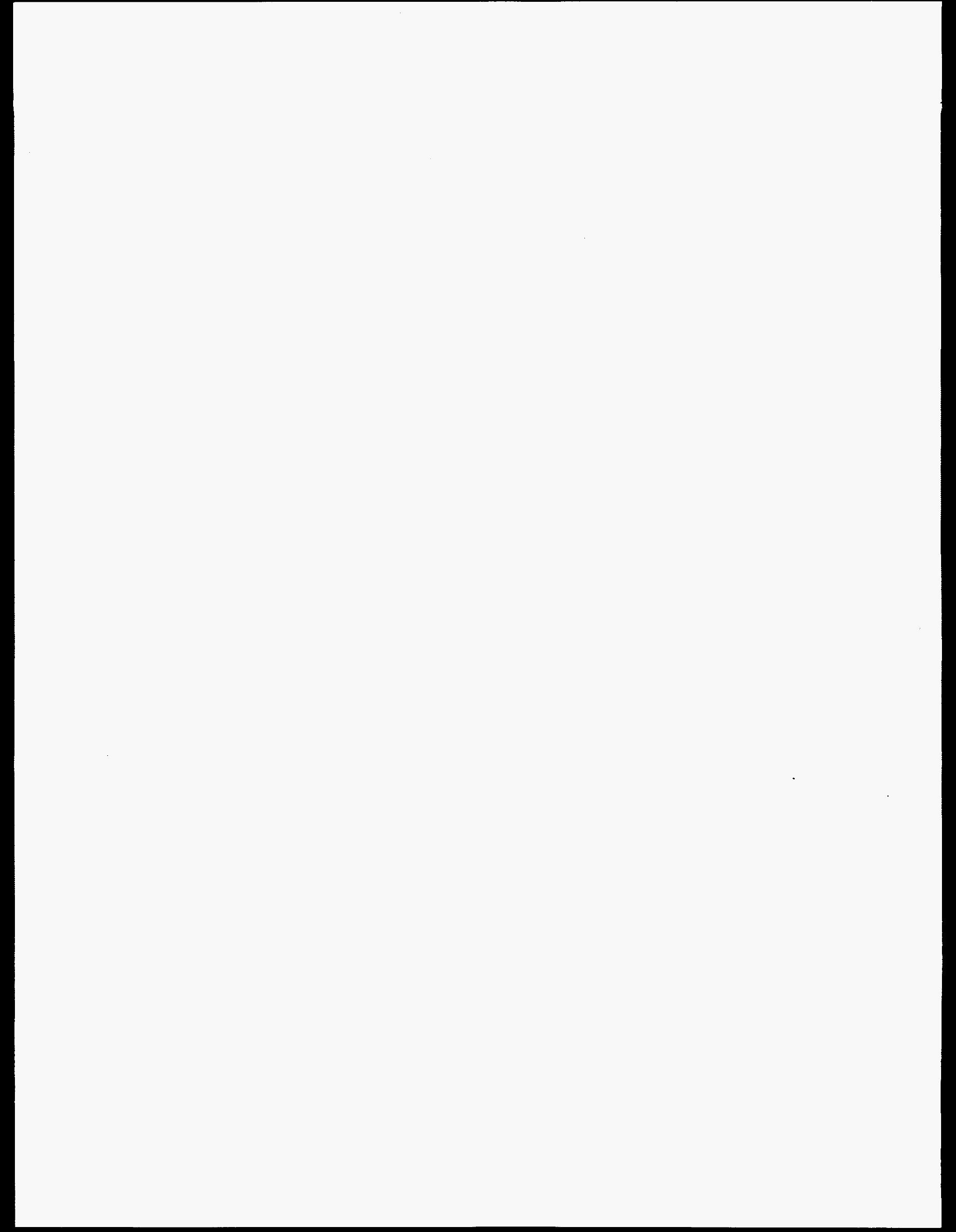




\section{TABLE OF CONTENTS}

ABSTRACT $\ldots \ldots \ldots \ldots \ldots \ldots \ldots \ldots \ldots \ldots \ldots \ldots \ldots \ldots \ldots \ldots \ldots$ iii

LIST OF FIGURES $\ldots \ldots \ldots \ldots \ldots \ldots \ldots \ldots \ldots \ldots \ldots \ldots$ vii

LIST OF TABLES $\ldots \ldots \ldots \ldots \ldots \ldots \ldots \ldots \ldots \ldots \ldots \ldots \ldots \ldots \ldots \ldots$ ix

VOLUME 2: LIST OF APPENDICES $\ldots \ldots \ldots \ldots \ldots \ldots \ldots \ldots \ldots \ldots \ldots$ xi

EXECUTIVE SUMMARY $\ldots \ldots \ldots \ldots \ldots \ldots \ldots \ldots \ldots \ldots \ldots \ldots$ xiii

PARTICIPANTS IN THE STUDY $\ldots \ldots \ldots \ldots \ldots \ldots \ldots \ldots \ldots \ldots$ xvii

ACKNOWLEDGMENTS $\ldots \ldots \ldots \ldots \ldots \ldots \ldots \ldots \ldots \ldots \ldots \ldots \ldots$ xix

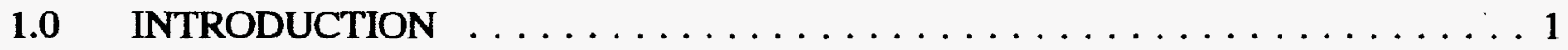

2.0 GOALS AND SCOPE OF STUDY $\ldots \ldots \ldots \ldots \ldots \ldots \ldots \ldots \ldots \ldots$

3.0 ANALYSES AND RESULTS $\ldots \ldots \ldots \ldots \ldots \ldots \ldots \ldots \ldots$

3.1 Method of Analysis $\ldots \ldots \ldots \ldots \ldots \ldots \ldots \ldots \ldots$

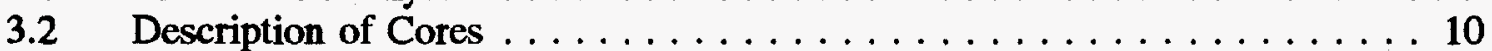

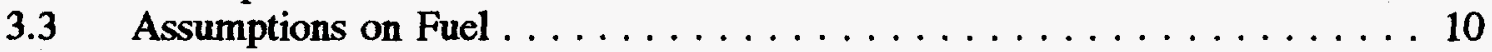

3.4 Description of the Quality Assurance Process $\ldots \ldots \ldots \ldots \ldots \ldots \ldots 12$

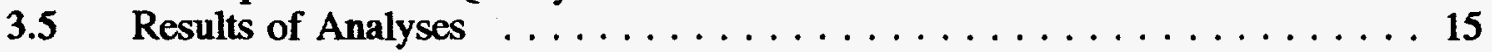

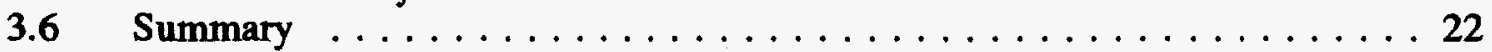

4.0 EVALUATION OF THE FUEL EXPERTS PANEL $\ldots \ldots \ldots \ldots \ldots \ldots \ldots$

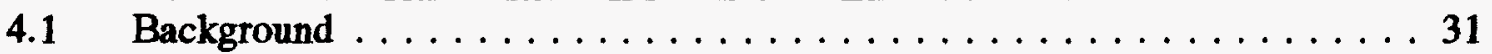

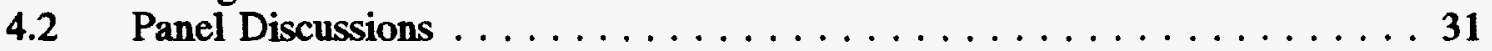

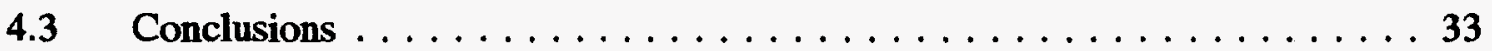

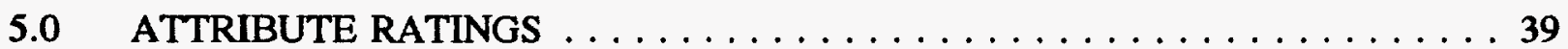

$5.1 \quad$ Thermal Neutron Flux $\ldots \ldots \ldots \ldots \ldots \ldots \ldots \ldots \ldots \ldots \ldots \ldots$

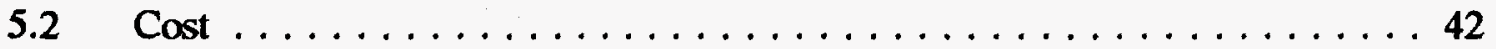

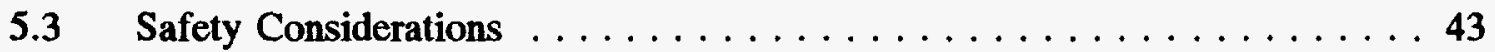

5.4 Safeguards Considerations $\ldots \ldots \ldots \ldots \ldots \ldots \ldots \ldots \ldots \ldots \ldots$

5.5 Multi-attribute Rating Methods $\ldots \ldots \ldots \ldots \ldots \ldots \ldots \ldots \ldots \ldots$

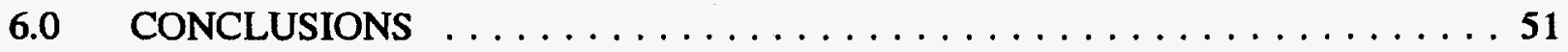

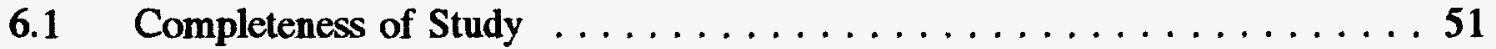

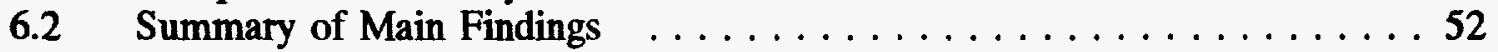




\section{LIST OF FIGURES}

Number

Title

Page

3.1 Dimensions of the Conceptual 2 Element Core Design (67.6 L) . . . . . . . 23

3.2 Dimensions of the Conceptual 3 Element Core Design (82.6 L) . . . . . . . . . 24

3.3 Dimensions of the Conceptual 3 Element Core Design (108 L) . . . . . . . . . 25

3.4 Thermal Conductivities of Candidate HWR-NPR Fuels as a Function of the Volume Fraction of Fuel + Voids $\ldots \ldots \ldots \ldots \ldots \ldots$

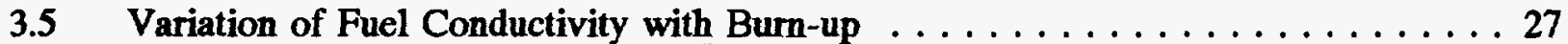

3.6 Relative Flux as a Function of $(P)^{1 / 3}(\rho)^{2 / 3} \ldots \ldots \ldots \ldots \ldots \ldots \ldots$

3.7 Relative Flux as a Function of Enrichment . . . . . . . . . . . . . . . . . . . . . 29

$4.1 \quad$ Hypothetical Temperature Profile of Concern . . . . . . . . . . . . . . . 37

4.2 Effect of Fuel Density on the Cost and Success Probability of the Fuel Development Program . . . . . . . . . . . . . . . . . . . . 38

5.1 Variation of the Critical Mass of Bare Uranium Spheres with Enrichment . . . . . . 50

6.1 Two-Element Core Event Tree $\ldots \ldots \ldots \ldots \ldots \ldots \ldots \ldots$

6.2 Small Three-Element Event Tree $\ldots \ldots \ldots \ldots \ldots \ldots \ldots \ldots$

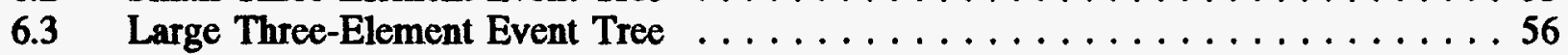





\section{LIST OF TABLES}

Number

3.1 Core Arrangements Studied $\ldots \ldots \ldots \ldots \ldots \ldots \ldots \ldots \ldots \ldots \ldots$

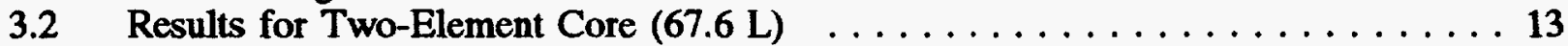

3.3 Results for Three-Element Core $(82.6 \mathrm{~L}) \ldots \ldots \ldots \ldots \ldots \ldots \ldots \ldots \ldots$

3.4 Results for Three-Element Core $(108 \mathrm{~L}) \ldots \ldots \ldots \ldots \ldots \ldots \ldots \ldots$

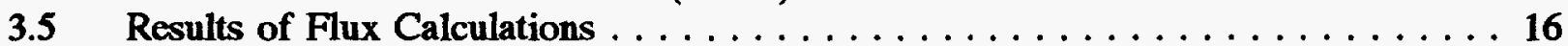

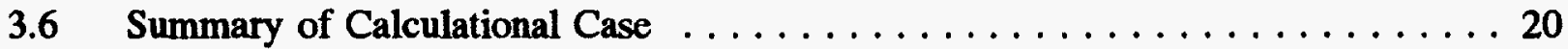

3.7 Summary of Estimates of Peak Fuel Centerline Temperature .......... 21

4.1 Relative Manufacturing Difficulty for Possible ANS Fuel Materials $\ldots \ldots \ldots \ldots 35$

4.2 Relative Concerns About Fuel Performance in ANS $\ldots \ldots \ldots \ldots \ldots \ldots, \ldots \ldots$

4.3 Effect of Design Fuel Density on ANS Program ................ 36

5.1 Comparisons of Performance for Various Cores $\ldots \ldots \ldots \ldots \ldots \ldots \ldots$

5.2 Relative Peak Thermal Neutron Flux for Various Enrichments and Core Sizes ... . 41

5.3 Fuel Density as a Function of Enrichment for Constant Power and Cycle Length . . 41

5.4 Cost Changes as a Function of Enrichment for Constant Power and Cycle Length

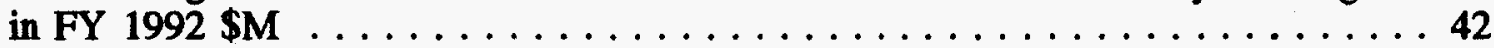

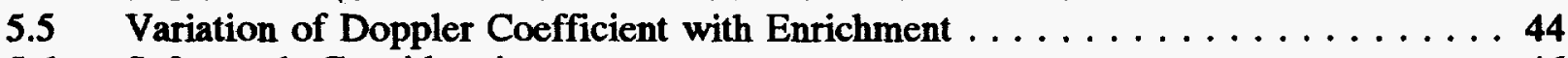

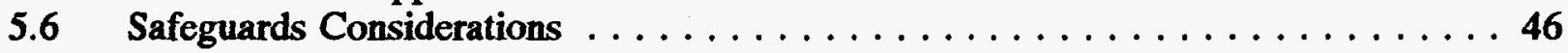

5.7 Multi-attribute Rating of Nineteen Reactor Configurations $\ldots \ldots \ldots \ldots \ldots$ 



\section{VOLUME 2: LIST OF APPENDICES}

\section{Appendix}

\section{Description}

Project Structure and Study Group $\ldots \ldots \ldots \ldots \ldots \ldots \ldots \ldots \ldots$

Minutes of 1st Meeting $\ldots \ldots \ldots \ldots \ldots \ldots \ldots \ldots \ldots \ldots \ldots \ldots$

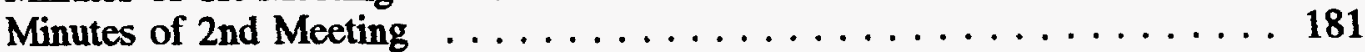

Letter from D. L. Selby to R. A. Bari . . . . . . . . . . . . . 311

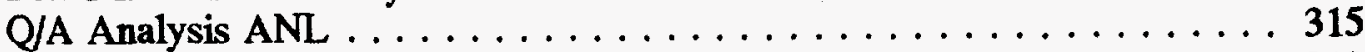

Q/A Analysis BNL . . . . . . . . . . . . . . . . . . . . 319

ANL Evaluation of the Thermal Conductivity of $6.5 \mathrm{gU} / \mathrm{cc} \mathrm{U}_{3} \mathrm{Si}_{2}-\mathrm{Al} \ldots{ }^{2} \ldots$

Results of ORNL Analysis . . . . . . . . . . . . . . 331

Sensitivity of Fuel Density to Change in Reactivity . . . . . . . . . . 341

Discussion of Fuel Centerline Temperature . . . . . . . . . . . . 345

Fuel Panel Attendees . . . . . . . . . . . . . . . . . 351

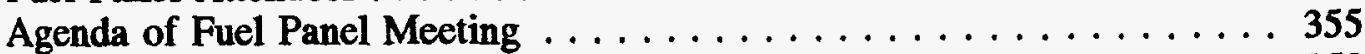

Minutes of Fuel Panel Meeting . . . . . . . . . . . . . . 359

Fuel Panel Presentation - R. A. Bari $\ldots \ldots \ldots \ldots \ldots \ldots \ldots$

Fuel Panel Presentation - F. J. Peretz . . . . . . . . . . . 371

Fuel Panel Presentation - G. L. Copeland . . . . . . . . . . . . . . 405

Fuel Panel Presentation - G. L. Hofman . . . . . . . . . . . . . . . . . 419

Fuel Panel Presentation - J. L. Snelgrove . . . . . . . . . . . . . . 441

Fuel Panel Presentation - Y. Fanjas . . . . . . . . . . . . . 461

Fuel Panel Presentation - R. Hobbins $\ldots \ldots \ldots \ldots \ldots$. . . . . . 481

Fuel Panel Presentation - Y. Fanjas . . . . . . . . . . . . . . 485

ORNL Cost and Schedule Evaluation . . . . . . . . . . . . . . . . 497

Evaluation of Cost and Schedule Evaluation . . . . . . . . . . . . 563

Nuclear Materials/Safeguards Categories . . . . . . . . . . . . . . . 567

Minutes of 3rd Meeting . . . . . . . . . . . . . . . . . 577

Minutes of 4 th Meeting $\ldots \ldots \ldots \ldots \ldots \ldots \ldots \ldots$ 



\section{EXECUTIVE SUMMARY}

The Advanced Neutron Source is a nuclear reactor that is being designed by Oak Ridge National Laboratory and sponsored by the U.S. Department of Energy. Its purpose is to produce intense quantities of neutrons for use in fundamental and applied research in physics, chemistry, biology, medicine, and materials technology. The performance goal is to build a machine with a neutron beam intensity, or flux, that is at least five times higher than existing facilities. The Advanced Neutron Source will be a more powerful research tool than existing facilities and will replace some facilities after their useful lifetime is over.

As with all other research reactors that have been operated to produce a very high flux of neutrons, the Advanced Neutron Source is designed to burn highly enriched uranium (HEU) fuel; this means that the fuel is composed of $93 \%$ of the isotope ${ }^{233} \mathrm{U}$ and $7 \%$ of the isotope ${ }^{238} \mathrm{U}$. With this mix, the design meets the performance goal, has acceptable safety characteristics, and is feasible to build within state-of-the-art engineering practices and cost envelopes.

Considerable effort has gone into designing of the reactor over the past several years, and the design has evolved as new information became available or requirements were imposed. The budget guidance for fiscal 1994 for the Advanced Neutron Source included the directive that a study be conducted of the impact on performance of using medium-enriched uranium (MEU) fuel or of using low-enriched (LEU) fuel. MEU contains a mix of $35 \% / 65 \%$ of ${ }^{235} U /{ }^{238} U$, and LEU contains a mix of $20 \% / 80 \%$ of ${ }^{235} U /^{238} U$. The Department of Energy asked Brookhaven National Laboratory to lead this Enrichment Study.

The reason for this study is the concern that some countries that have, or plan to have, HEUfueled research reactors may find themselves in a situation in which the HEU fuel is diverted for non-peaceful purposes. Thus, the logic goes, if the United States forgoes HEU in its Advanced Neutron Source, other countries might follow our example. Compared to LEU or MEU, HEU is much more attractive to those who would divert uranium fuel for weapons. For perspective, a prompt critical system (consisting of an unmoderated, unreflected sphere of uranium metal) based on HEU involves approximately 50 kilograms, while a half tonne and one tonne are the corresponding approximate quantities for MEU and LEU, respectively. The total uranium content for the existing design of the Advanced Neutron Source is approximately 25 kilograms.

Three other national laboratories with special expertise in fuel enrichment studies of research reactors, participated in the Brookhaven Study. Argonne National Laboratory, which has extensively evaluated HEU to LEU conversions of research reactors worldwide, Oak Ridge National Laboratory, which designed the Advanced Neutron Source, and Idaho National Engineering Laboratory, which contributed technically to the design, and has much experience in designing research and test reactors. For this cooperative study; the participants agreed upon a mode of technical inquiry and on work assignments for each laboratory. The results of interim studies were evaluated critically by the four laboratories in open interchanges, areas for further investigation were defined, and tentative conclusions were made. This information was readily available to all participants. Between meetings of the Study Group, the participants performed analyses at their respective institutions. During the study, a special expert panel on fuels was 
convened to assess the feasibility of developing and manufacturing a postulated form of fuel that would be needed in the reactor at lower enrichments. The panel was composed of international experts in fuel design, manufacture, and performance; the conclusions of this panel also are included in this study.

The scope of the Enrichment Study, as defined by the Department of Energy, was to work within the existing design of the reactor, not to produce a much higher power reactor that would greatly increase the capital costs, and to investigate the implications of using a hypothetical fuel with material density approximately five times greater than the fuel specified for the existing design.

The Study Group determined that two parameters should be varied independently to assess the impact of using either MEU or LEU in the reactor. One parameter is uranium fuel density, which would be increased to approximately compensate for decreased ${ }^{235} U$ content in the lower enriched fuels. The other parameter is the reactor core's volume, which would be increased to compensate for reactivity losses that would result from lowering the enrichment. Thus, the fuel density was varied from the existing design value of $1.7 \mathrm{gU} / \mathrm{cc}$ to values in excess of $6 \mathrm{gU} / \mathrm{cc}$ (in response to the directive of the Department of Energy). In addition to the existing core volume of $67.6 \mathrm{~L}$, analyses were performed for two larger volume cores; $82.6 \mathrm{~L}$ and $108 \mathrm{~L}$. The existing core has two cylindrical-shell fuel elements, and the two larger cores each contain three cylindrical-shell fuel elements. The $108 \mathrm{~L}$ core is a hypothetical example that was configured to study the physics behavior of a large core. In practice, the design could suffer from large, unsafe deflections of the fuel plates due to forces acting on the wide, relatively flat, and, therefore, flexible plate span. Additional research and development would be required to investigate the mechanical, fluid dynamic, heat transfer, and safety implications of this larger core.

Many potential configurations of fuel density, enrichment, and core volume were analyzed; only those that met criteria for sufficient initial reactivity, acceptably safe power density and fuel temperature, and the capability of sustaining an acceptable core life (at least 17 days) were considered further. However, a wider range of configurations was considered than are either feasible or desirable to enhance our intuition about the impact of parametric variations.

The existing (or reference) reactor design contains $93 \%{ }^{235} \mathrm{U}$ enrichment, a fuel density of 1.7 $\mathrm{gU} / \mathrm{cc}$, and operates at 330 megawatts. Based on the many configurations evaluated, the following main conclusions are drawn.

1. HEU is better than lower enriched uranium fuels for the flux performance of the Advanced Neutron Source; in particular, the MEU and LEU configurations consistently led to an inferior flux performance.

2. If the enrichment were reduced to $35 \%$ (MEU), then a reactor configuration was identified which meets the above criteria. In this reactor, the core volume would be increased to $82.6 \mathrm{~L}$, the fuel density would be increased to $3 \mathrm{gU} / \mathrm{cc}$, the power would remain at 330 megawatts, but the resulting neutron flux would be approximately $20 \%$ less than in the existing design. The additional cost of the project, above the current cost of 
the existing design $(\$ 2.7 \mathrm{~B})$, would be approximately $\$ 0.4$ billion. This increase mostly is due to an increase in operating costs over the lifetime of the plant. Only an additional $\$ 5 \mathrm{M}$ additional would be needed for total project costs. The uranium mass of the core would be approximately $60 \mathrm{~kg}$, and, from a safeguards perspective, 7 full cores would be required to achieve a prompt critical system.

3. If the enrichment were reduced to $20 \%$, then a reactor could be designed within the confines of the technology used for the reference plant. The core volume would be increased to $82.6 \mathrm{~L}$, the fuel density would be increased to $3.5 \mathrm{gU} / \mathrm{cc}$ (the practical upper limit), the power would have to be decreased to 125 megawatts, and the resulting neutron flux would be approximately $70 \%$ less than in the existing design. The additional cost of the project would be approximately $\$ 90$ million, namely, a $\$ 160 \mathrm{M}$ increase in operating costs over the plant's lifetime relative to the reference plant, but a $\$ 70 \mathrm{M}$ decrease in total project costs because this reactor would operate at much lower power. At this enrichment, more than 13 full cores would be needed to achieve a prompt critical system.

These main conclusions are given for configurations that would have the best technical chance of succeeding for the stated enrichments, and with the derived flux and cost penalties. For MEU fuel, other reactors can be designed for which the flux penalty relative to the existing design would be approximately $10 \%$. This penalty can be achieved by increasing the power in the MEU case described in item 2 to 405 megawatts, the maximum permissible based on considerations of heat removal, and increasing the fuel density to $3.5 \mathrm{gU} / \mathrm{cc}$. The additional cost of this design is $\$ 0.5 \mathrm{~B}$, relative to the reference design. A high flux also can be achieved with MEU by increasing the fuel density to $6.5 \mathrm{gU} / \mathrm{cc}$ in the reference core volume, with power at 330 megawatts. However, the Fuel Experts Panel concluded that a program to develop fuel with a density $6.5 \mathrm{gU} / \mathrm{cc}$, to the narrow tolerances required for a high performance, reactor has more than a $90 \%$ chance of failure.

For LEU fuel, reactors can be designed with a less severe flux penalty than described in item 3. Thus, a LEU that has a $35 \%$ flux penalty relative to the reference design, would operate at 330 megawatts in the largest core volume, $108 \mathrm{~L}$, and requires a fuel density of $4.8 \mathrm{gU} / \mathrm{cc}$. Again, the Fuel Experts Panel judged that chances of developing such a fuel for the Advanced Neutron Source are highly unlikely. Higher fluxes can be achieved by increasing the power in this core to 430 megawatts and increasing the fuel density to $5.8 \mathrm{gU} / \mathrm{cc}$; this implies a flux penalty of approximately $20 \%$. In addition, research and development would be needed to assess the technical feasibility of the $108 \mathrm{~L}$ core.

The Study Group also evaluated the impact of reducing the enrichment of the fuel to $80 \%, 50 \%$, and to $45 \%$. For the first case, no significant differences with fully enriched fuel were found in performance, cost, technical feasibility, or safety. Two full cores (4 elements) would be needed to achieve a prompt critical system. For $50 \%$ enrichment, the flux penalty could be limited to $10 \%$, provided that the power is increased to 400 megawatts in the $82.6 \mathrm{~L}$ core. The fuel density would be increased to the reasonably achievable value of $2.2 \mathrm{gU} / \mathrm{cc}$, but the additional operating costs would be $\$ 0.5$ billion over the life of the facility. About 4 fuel elements would be needed 
to achieve a prompt critical system. The $45 \%$ enrichment cases were studies of lower power density in the $67.6 \mathrm{~L}$ and $82.6 \mathrm{~L}$ core volumes. Both gave approximately $40 \%$ flux penalties with fuel densities that do not exceed $3.5 \mathrm{gU} / \mathrm{cc}$.

In summary, the Enrichment Study Group found that although it would be feasible to redesign the Advanced Neutron Source to operate with MEU or LEU fuels, such designs would significantly reduce performance and increase cost. Other designs, which could maintain performance, would incur significant additional costs required for extensive development work, and moreover, would have a high probability of technical failure. 


\section{ADVANCED NEUTRON SOURCE ENRICHMENT STUDY}

Participants in the Study

\section{Brookhaven National Laboratory}

R. A. Bari

H. Ludewig

M. Todosow

J. Weeks

B. Keisch

L. Forman

M. Blume*

S. Baron*

M. Brooks*

*Steering Group

Argonne National Laboratory
A. Travelli
J. Matos
J. Snelgrove
G. Hofman

Oak Ridge National Laboratory
C. West
D. Selby
G. Copeland
F. Peretz
P. Thompson
B. Worley
J. Gehin

Idaho National Engineering Laboratory
J. Ryskamp
C. Wemple
A. Ougouag

\section{Others}
R. Hobbins
H. Kalish
J. Marks
Y. Fanjas
H. Peacock 



\section{ACKNOWLEDGMENTS}

We are grateful for the support, encouragement, and guidance of R. Hunter, J. Mulkey, and R. Awan of the Department of Energy. 


\subsection{INTRODUCTION}

The Advanced Neutron Source (ANS) is a nuclear reactor that is being designed by Oak Ridge National Laboratory (ORNL) and a number of collaborators under the sponsorship of the U. S. Department of Energy. Its purpose is to produce intense quantities of neutrons for use in fundamental and applied research in physics, chemistry, biology, medicine, and materials technology. The performance goal is to build a machine with a neutron beam intensity, or flux, that is at least five times higher than existing facilities. The Advanced Neutron Source will be a more powerful research tool than existing facilities and will replace some facilities after they reach the end of their useful lifetime.

As with all other research reactors that have been operated for producing a very high flux of neutrons, the Advanced Neutron Source is designed to burn highly enriched uranium (HEU) fuel; this means that the fuel contains $93 \%$ of the isotope ${ }^{233} \mathrm{U}$, and $7 \%$ of the isotope ${ }^{238} \mathrm{U}$. With this mix, the design meets the performance goal, has acceptable safety characteristics, and is feasible to build within state-of-the-art engineering practices and cost envelopes.

Considerable effort has gone into designing the reactor over the past several years, and the design has evolved as new information became available or requirements were imposed. The budget guidance for fiscal 1994 for the Advanced Neutron Source included the directive that a study be made of the impact on performance of using medium-enriched uranium (MEU) fuel or lowenriched (LEU) fuel. MEU contains a mix of $35 \% / 65 \%$ of ${ }^{235} U /{ }^{238} U$, and LEU has $20 \% / 80 \%$ of ${ }^{235} \mathrm{U} /{ }^{238} \mathrm{U}$. The Department of Energy asked Brookhaven National Laboratory (BNL) to lead this Enrichment Study.

The reason for this study is the concern that some countries that have, or plan to have, HEUfueled research reactors may find themselves in a situation in which the HEU fuel is diverted for non-peaceful purposes. Thus, the logic goes, if the United States forgoes HEU in planning the Advanced Neutron Source, other countries might follow our example. Compared to LEU or MEU, HEU is much more attractive to those who would divert uranium fuel for weapons. For perspective, a prompt critical system (consisting of an unmoderated, unreflected sphere of uranium metal) based on HEU involves approximately 50 kilograms, while a half tonne and one tonne are the corresponding approximate quantities for MEU and LEU, respectively. The total uranium content for the existing design of the Advanced Neutron Source is about 25 kilograms.

Three other national laboratories with special expertise in fuel enrichment studies of research reactors participated in the BNL study; Argonne National Laboratory (ANL), which has extensively evaluated HEU to LEU conversions of research reactors worldwide; Oak Ridge National Laboratory, which designed Advanced Neutron Source; and Idaho National Engineering Laboratory (INEL), which contributed technically to the design, and has much experience in designing research and test reactors. For this cooperative study, the participants collectively agreed upon a mode of technical inquiry and on work assignments for each laboratory. A set of calculations were agreed upon for various enrichments, core volumes, and fuel densities. Technical criteria for the acceptability of results were defined. To perform the analyses within the confines of the schedule, it was decided that Oak Ridge National Laboratory and Idaho

December 31, 1994 
National Engineering Laboratory should run the computer cases that the four laboratories agreed upon. Argonne National Laboratory and Brookhaven National Laboratory made quality assurance checks of the calculations by running selected cases at their own organizations and with their codes. The results of interim studies were evaluated jointly, areas for further investigation were defined, and tentative conclusions were made. All of the laboratories carefully and critically reviewed the key assumptions and results. Argonne and Brookhaven requested additional calculations, which then were available to all participants. Between meetings of the Study Group, the participants performed analysis at their respective institutions.

The project was led by BNL, composed of experts, who, in turn, reported to a senior advisory group. Appendix 1 shows the organization and project structure of the Study Group. The participants in the study are listed in the inside cover pages of this report. The minutes of the meeting held at Brookhaven on September 22, 1993 are given as Appendix 2, and those of the meeting in San Francisco on November 16-17, 1993 are given in Appendix 3. During the study, a special panel of international experts in fuel technology was convened, on December 14-15, 1993, to assess the feasibility of developing and manufacturing a postulated fuel form that would be needed in the reactor at lower enrichments. The panel's conclusions are also included in Chapter 4. The list of members and presentations at their meeting are given in the appendices. A draft preliminary version of this report was sent to the participants on December 31, 1993 for review and comments. In 1994, this draft report was sent, upon request, to several government agency representatives, consultants, contractors, and non-government organizations. On January 14, 1994, Brookhaven National Laboratory met with DOE to review progress on the study. The study group met again on January 21, 1994 to review the comments of the participants on the draft preliminary report. Appendix 25 summarizes that meeting. On February 2, 1994, a second briefing on the results of the Study was given to members of the DOE Offices of Nuclear Energy and Energy Research, particularly emphasizing the discussions to the engineering feasibility of design alternatives. On February 23, 1994, at the request of DOE, a briefing on the results was given to representatives of the Nuclear Control Institute and the Natural Resources Defense Council (a representative of Greenpeace also was invited but did not attend). The focus there was on fuel enrichment and non-proliferation concerns. The results were presented on July 21, 1994 to the DOE Basic Energy Sciences Advisory Committee and the National Steering Committee for the Advanced Neutron Source. The emphasis in these discussions was flux performance. On July 22, 1994, the fourth meeting of the Study Group discussed the verification calculations performed by Argonne National Laboratory. Appendix 26 has the summary of that meeting. On September 20, 1994, a paper based on the Study was presented at the 1994 Conference on Reduced Enrichment for Research and Test Reactors in Wiliamsburg, VA. Finally, the results of the Study were presented at the U.S./German Technical Information Exchange Meeting in Knoxville, TN on November 2, 1994. The meeting also included a status report by the German representatives on the design of their FRM-II which currently is planned to be constructed and operated with HEU fuel. Some conclusions of the Study appear in the November, 1994 issue of Physics Today (pp. 17-19) and in the November 18, 1994 issue of Science (pp. 1160-1161) taken from interviews with one of the authors of this report.

Chapter 2 of this report gives Goal and Scope of the study, Chapter 3 contains Analysis and Results, Chapter 4 summarizes the Fuel Experts Panel evaluation, Chapter 5 gives Performance 
Ratings, and Chapter 6 presents the conclusions. Various Appendices that provide supporting and background information are included in a second volume. 



\subsection{GOALS AND SCOPE OF STUDY}

The goal of the study was to determine the impact on the Advanced Neutron Source (ANS) performance goals if low- or medium-enriched (percentage of ${ }^{235} \mathrm{U}$ ) fuel were used rather than the highly enriched $\left(93 \%{ }^{235} \mathrm{U}\right)$ fuel used for the baseline design. The study built on existing information of currently developed fuels and focused on low- (20\%) and medium- (35\%) enriched fuel. The ground rules of this study were that any alternative reactor designs would not change the existing beam tube positions, or significantly increase the power output of the current baseline design. The alternative designs are restricted to the same type of technology as the baseline design i.e. aluminum-clad uranium-silicide fuel in the form of plates, cooled by heavy water, and contained in an aluminum pressure vessel. The study was to be completed by February 1994, to assist DOE in establishing future plans.

The impact of using either low- or medium-enrichment fuel in the ANS was measured by considering the change in the following four parameters.

1. Neutron Flux - As a representative parameter, the maximum, unperturbed thermalneutron flux in the reflector was used as a measure of performance. The value of this flux was compared to the baseline design goal, which, in turn, was fixed at $7.0(19)^{*} \mathrm{n} / \mathrm{m}^{2}$ s. This measure of performance does not account for any possible changes in the spectrum associated with the alternative designs which could affect the performance of the ANS as a device for producing isotopes, or for carrying out epithermal irradiations. The flux at the beam-tube's mouth, which is of interest to the scientific user, is discussed in Section 3.5. Appendix 4 discusses these parameters.

2. Cost - Two components primarily determine the cost of the ANS construction and operating costs. Changes in the construction costs are a function of the reactor's power. Thus, significant deviations from the current operating power ${ }^{\star \star}(330 \mathrm{MW})$ will have an impact on the plant's cost. Changes in the operating cost will be dominated by the number of fuel elements fabricated and burned per year.

3. Safety - The safety impact of using lower enrichment uranium has several elements; first, the higher fertile content of the fuel will enhance the Doppler coefficient, reducing the demand on the control system; second, the higher fuel density required with lower enrichments will reduce the fuel's conductivity, and hence, increase the centerline temperature of the fuel, reducing the safety margin; third, lower enrichment cores may require larger volumes with radially longer fuel plates of lower curvature, which would be mechanically less stable at high coolant velocities; fourth, the power density in alternative core configurations must be kept within acceptable safety margins; and fifth, there would be increased plutonium build-up with irradiation, which would increase the cleanup following a severe accident.

${ }^{\star} 7.0(19)=7.0 \times 10^{19}$

** Operating power refers to fission power, not thermal power. 
4. Safeguards - The safeguards dimensions are measured in terms of the requirements of implementing U.S. safeguards programs as a function of enrichment, the potential for diversion of fuel elements, the production of plutonium, and the implications for international policy. This study was motivated by the latter. However, it was not the objective of this study to address or propose policy options nor international nonproliferation strategies. Rather, the study focused on the technical impact of using alternative enrichments for the fuel of the Advanced Neutron Source. The study did assess the implications of potential alternative designs for the DOE domestic safeguards program, on the number of cores that would be required for non-peaceful purposes, and on the amount of plutonium produced. These parameters provide a measure of the significance of designs with various enrichments and may be useful in determining the implications for international policy.

The scope of the Enrichment Study, as defined by the Department of Energy, was to work within the existing design of the reactor, not produce a higher power reactor that would drive up the capital costs, and to investigate the implications of using a hypothetical fuel with material density approximately five times greater than the fuel specified for the existing design. 


\subsection{ANALYSES AND RESULTS}

The following are the technical objectives of the ANS:

1. A neutron flux in the reflector available to the beam tubes that is $\mathbf{5}$ to $\mathbf{1 0}$ times higher than existing facilities,

2. Isotope production and material-irradiation facilities that are at least the equal of current facilities in the High Flux Isotope Reactor (HFIR).

Furthermore, the ANS design relies on proven, internationally accepted high flux reactor technology, and, thus, has the following features:

1. Involute fuel plate geometry,

2. Aluminum clad Cermet fuel,

3. Silicide fuel based on the Reduced Enrichment Research and Test Reactor (RERTR) program, and

4. Cold neutron source based on the Institute Laue Langevin (ILL) design.

The basic requirements for a core that is to generate a peak neutron flux in the reflector is to have a high power level, thus ensuring many fissions, and as small an outer surface area of the core as passible within the constraint of remaining critical throughout the cycle. For cores of similar composition and geometry, the thermal flux in the reflector is approximately proportional to reactor's power divided by core's surface area. Based on this assumption it can be shown that:

$$
\Phi_{\mathrm{t}} \approx \text { Constant } \mathrm{P}^{1 / \beta}(\rho)^{2 / \beta}
$$

Where

$$
\begin{aligned}
& P=\text { reactor power } \\
& \rho=\text { average reactor power density }
\end{aligned}
$$

This relationship shows that high power is beneficial, but high power density is even more desirable for high flux research reactors. The approximate validity of this relationship can be judged by comparing the "Constant" implied by the above equation for a variety of research reactors. Physically, this constant is a measure of the number of neutrons produced per unit of energy expended. 


\begin{tabular}{|c|c|}
\hline Reactor Facility & "Constant" (n/W-s) \\
\hline FRM-II* & $2.74(10)^{*}$ \\
\hline ILL & $3.15(10)$ \\
\hline ORPHEE & $3.14(10)$ \\
\hline NBSR & $3.81(10)$ \\
\hline HFBR & $3.87(10)$ \\
\hline ANS* & $3.23(10)$ \\
\hline
\end{tabular}

* $2.74(10)=2.74 \times 10^{10}$

* Approximate values, reactors in design

The approximate relationship between reflector flux, power, and power density is sufficiently accurate to estimate initial power and volume for a core of the desired performance. However, in estimating the various parameters of the core configuration, the following practical limits should be observed:

1. The power density should not exceed $4.88 \mathrm{MW} / \mathrm{L}$ for the level of technology being considered in this study (outlined above),

2. The variation in the fuel's conductivity with its density should be considered because the centerline fuel temperature is limited to $400^{\circ} \mathrm{C}$,

3. The coolant velocities limit the cross-sectional area (fuel plate span) of the elements because of limitations in the plate's stability, and

4. The lengths of the elements and thicknesses of the fuel plates should not be increased much beyond accepted limits to limit pressure and temperature gradients, and to prevent the core from becoming too heterogeneous.

The reduced reactivity of cores with lower enriched uranium can be compensated for by either increasing the fuel density, increasing the core volume at fixed fuel density, or increasing both. When the core volume is increased, the power level must be increased to maintain the desired flux level. Finally, all cores must contain sufficient fissile material to operate for a reasonable time before re-fueling is needed.

The above introductory comments will act as a backdrop for the analytic study of LEU and MEU cores for the ANS. 


\subsection{METHOD OF ANALYSIS}

The method of analysis employed in studying the effect of reduced enrichment fuel on the performance of the ANS included the following salient features:

1. Analyses of fuel cycles were performed for all cases in which transport theory (based on 3D MCNP continuous-energy Monte Carlo calculations) beginning of cycle (BOC) multiplication factor $\left(k_{\text {eff }}\right)$ is greater than or equal to 1.15 .

2. A two-dimensional R-Z model of the reactor was used in analyzing fuel cycles. Four group-diffusion theory calculations were used in assessing burn-up. Reflector components, such as beam tubes and cold sources, were smeared out in annular rings.

3. The control rod model represented in $R-Z$ geometry, consisting of smeared rings, is based on the explicit three-dimensional transport theory model referred to above.

4. Reflector shutdown rods, in-core transuranium production rods, and in-core irradiation targets were not modeled.

5. The following assumptions were made about fuel grading:

5.1. The reference core-fuel grading was used in all 2 -element cores.

5.2. A flat fuel distribution was used for all 3-element cores (no grading).

5.3. The fuel-volume displacement for the 2-element cores (due to grading) was used to represent loss of fuel displacement in the 3-element cores.

6. The total core power and minimum fuel densities for each case were chosen so that the control rods were fully withdrawn at end of a 17-day cycle.

7. After analyzing fuel cycles, MCNP-3D Monte Carlo model was used to obtain the base flux levels.

The three-dimensional Monte Carlo method was validated by comparison with the FOEHN critical experiments. These experiments were carried out in connection with the ILL reactor project, and are, therefore, an appropriate benchmark. The good agreement between MCNP and the FOEHN critical experiments essentially validates the code and data used in the comparison. The diffusion-theory-based burn-up code and a few group cross-sections (VENTURE system) were validated by comparison with the Monte Carlo calculations. 


\subsection{DESCRIPTION OF CORES}

The reactor cores considered included three different volumes, arranged in two geometric configurations, and using five uranium enrichments. The core volumes considered are $67.6 \mathrm{~L}$, 82.6 L, and $108 \mathrm{~L}$, arranged in a two-element, three-element, and a large three-element configuration, respectively (Figures 3.1-3.3). The two-element configuration shown in Figure 3.1 corresponds to the reference ANS geometry, and is used for all $67.6 \mathrm{~L}$ core representations. The three-element configuration shown in Figure 3.2 is used in all $82.6 \mathrm{~L}$ cores, and is based on the two-element reference core. Finally, the largest $108 \mathrm{~L}$ core shown in Figure 3.3 is based on the small three-element core with expanded fuel plate spans. In this respect, this core is not optimized mechanically, and can only be used to check the peak flux and fuel-cycle performance of the core.

Ten cores were considered initially to study the feasibility of LEU or MEU options for the ANS. Subsequently, nine additional cores were added to enhance understanding of the range of results and trends. All the cores are required to meet the 17-day cycle, and have an acceptable power density. In addition, all cores, except the $125 \mathrm{MW}$ core, have an estimated performance that is within $50 \%$ of the reference core value. These cores are given in Table 3.1, with their fuel density, power, and uranium enrichment.

\subsection{ASSUMPTIONS ON FUEL}

The core arrangements outlined in Table 3.1 show a wide range of enrichments (20\% - 93\%), and a correspondingly wide range in estimated fuel densities $(1.7 \mathrm{gU} / \mathrm{cc}-7.2 \mathrm{gU} / \mathrm{cc})$. In the Reduced Enrichment Research and Test Reactor (RERTR) program, $\mathrm{U}_{3} \mathrm{Si}_{2}-\mathrm{Al}$ fuel was qualified to a density of $4.8 \mathrm{gU} / \mathrm{cc}$. However, it is not clear whether this fuel would meet the heat transferburn-up level and rate requirements of the ANS. Current density estimates of silicide based uranium fuels, which satisfy the ANS burn-up requirements, limit the fuel to $3.5 \mathrm{gU} / \mathrm{cc}$. Both these practical limits of fuel density are well below the highest estimated required densities in Table 3.1. However, the feasibility of a fuel development program was assessed by a panel of experts. Their findings, presented in the next chapter, focused on the probability of success, time required, and cost of achieving the desired higher densities.

Higher density fuels are required in the case of lower enrichments because there must be sufficient fissile material in the core to ensure criticality for the entire 17-day cycle. These higher density fuels have the following properties that affect the reactor's design:

1. The thermal conductivity of any admixture of a ceramic uranium compound (e.g., $\mathrm{U}_{3} \mathrm{Si}_{2}$, $\mathrm{U}_{3} \mathrm{O}_{8}$ ) and aluminum to form the meat in a plate-type fuel element decreases with increasing uranium content. Thus, Figure 3.4 shows that for a density of $1.3 \mathrm{gU} / \mathrm{cc}$, the conductivity is approximately $180 \mathrm{~W} / \mathrm{m}-\mathrm{K}$, while for $5.0 \mathrm{gU} / \mathrm{cc}$ the value has dropped to $30 \mathrm{~W} / \mathrm{m}-\mathrm{K}$. The variation of conductivity with burn-up, at a given density, is an initial increase, and finally a decrease. The initial increase is due to swelling of the fuel particles, improving the contact between the aluminum matrix and the fuel, so improving 
conductivity. The eventual decrease presumably is due to continued swelling from the generation of fission product gas, disrupting the fuel/aluminum matrix, and leading to a decrease in conductivity. The variation of conductivity with burn-up, illustrated in Figure 3.5 for a density of $3.5 \mathrm{gU} / \mathrm{cc}$, shows that it increases from approximately $102 \mathrm{~W} / \mathrm{m}-\mathrm{K}$ to $109 \mathrm{~W} / \mathrm{m}-\mathrm{K}$, and then decreases monotonically to $75 \mathrm{~W} / \mathrm{m}-\mathrm{K}$. ANL made a specific assessment of the thermal conductivity for a fuel density of $6.5 \mathrm{gU} / \mathrm{cc}$; they found that conductivity would be no greater than $10 \mathrm{~W} / \mathrm{m}-\mathrm{K}$ (see Appendix 7).

Table 3.1 - Core Arrangements Studied

\begin{tabular}{|c|c|c|c|c|c|}
\hline Case & $\begin{array}{c}\text { Number of } \\
\text { Elements }\end{array}$ & $\begin{array}{c}\text { Volume } \\
(\mathrm{L})\end{array}$ & $\begin{array}{c}\text { Enrichment } \\
(\%)\end{array}$ & $\begin{array}{c}\text { Fuel } \\
\text { Density } \\
(\mathrm{gU} / \mathrm{cc})\end{array}$ & $\begin{array}{c}\text { Power } \\
(\mathrm{MW})\end{array}$ \\
\hline 1 & 2 & 67.6 & 93 & 1.7 & $330^{*}$ \\
2 & 2 & 67.6 & 80 & 2.1 & 330 \\
3 & 3 & 82.6 & 50 & 2.0 & 330 \\
4 & 3 & 82.6 & 50 & 2.2 & 400 \\
5 & 3 & 82.6 & 35 & 3.5 & 405 \\
\hline 6 & 3 & 82.6 & 35 & 3.0 & 330 \\
7 & 3 & 108.0 & 20 & 7.2 & $530 *$ \\
8 & 3 & 108.0 & 20 & 6.0 & 449 \\
9 & 3 & 82.6 & 20 & 3.5 & 125 \\
10 & 3 & 108.0 & 20 & 4.8 & 330 \\
\hline 11 & 2 & 67.6 & 35 & 6.5 & 330 \\
12 & 3 & 82.6 & 50 & 2.0 & 340 \\
13 & 3 & 82.6 & 35 & 3.3 & 370 \\
14 & 3 & 108.0 & 20 & 5.8 & 430 \\
15 & 3 & 82.6 & 93 & 1.0 & 330 \\
\hline 16 & 2 & 67.6 & 45 & 3.5 & 200 \\
17 & 3 & 82.6 & 45 & 1.8 & 250 \\
18 & 3 & 82.6 & 35 & 2.1 & 200 \\
19 & 3 & 108.0 & 35 & 1.8 & 260 \\
\hline
\end{tabular}

*Used in this reactivity sensitivity study. 
2. The implication of lower conductivity with increasing fuel density is that the fuel's centerline temperature will increase, assuming a similar power density. The centerline temperature is limited by the fuel's properties and by the requirement that the fuel plates are stable to $400^{\circ} \mathrm{C}$. Furthermore, to satisfy the requirement that the technological level does not vary significantly from the current level, the fuel plate's design and the widths of the coolant channels limit the volume of the active core available for fuel to approximately $25 \%$. This limit and the conductivity limitations set an upper bound on the feasible combinations of power level and core life.

3. Higher fuel densities will make the core blacker to neutrons, thus reducing the leakage; therefore, at the same power level, the flux in the reflector will decrease with increasing fuel density. To achieve the same performance as a core using lower density fuel, the power level of the core using higher density fuel will have to be increased to compensate for this shortfall.

In the following sections, the results of the analyses are discussed with the implied limitations due to fuel conductivity and reactor design in mind.

\subsection{DESCRIPTION OF THE QUALITY ASSURANCE PROCESS}

The quality assurance (Q/A) process forms an integral aspect of the project's analysis work. A two-pronged approach was taken. First, the numerical techniques were validated against all relevant critical experiments. (This step was alluded to above in the methods section). The Monte Carlo physics methods were judged by their ability to reproduce the measured results of the FOEHN experiments (see Appendix 3 for this evaluation). All other physics methods, diffusion theory, and deterministic transport theory were judged by their ability to reproduce the Monte Carlo results. Second, ANL and BNL staff independently checked selected core analyses. For Monte Carlo calculations, this consisted primarily of checking the consistency of the input parameters, and executing selected problems. For the burn-up calculations, the ANL team started with a description of the core and created an independent input file which was executed on their software package. In this manner both the Monte Carlo and burn-up steps of the analysis were checked.

The cores chosen for the validation exercise were:
1) 2 element
$67.6 \mathrm{~L}$
2) 3 element
$82.6 \mathrm{~L}$
93\% enriched
$1.7 \mathrm{gU} / \mathrm{cc}$
3) 3 element
$108 \mathrm{~L}$
$35 \%$ enriched
$3.5 \mathrm{gU} / \mathrm{cc}$
$20 \%$ enriched
$6.0 \mathrm{gU} / \mathrm{cc}$

This selection spans a representative range in core volumes, enrichments, and fuel densities. In addition, all these cores were projected to be within $20 \%$ of the projected goal performance.

Quality assurance discussions from ANL and BNL are included in Appendices 5 and 6, respectively. In summary, eigenvalue comparisons for cases with fully withdrawn control rods, show an agreement of approximately $\pm 2 \%$ between $\mathrm{ANL}$ and ORNL calculations. These 
comparisons were made with both Monte Carlo methods and diffusion theory. The correct representation of control rod followers was found to be important, particularly for large cores. Light water impurity is worth approximately $-0.9 \%$ in $\mathbf{k}_{\text {off }}$. Monte Carlo calculations agreed very closely with those carried out at INEL using different versions of the MCNP code. To extend the quality-assurance process, and quantify the uncertainties in the analysis, burnup calculations were carried out for the three cores. Both ORNL and ANL analyzed these cores using their respective analysis methods, namely, the VENTURE system, and the REBUS system, respectively. Both these systems are based on diffusion theory, and thus are inherently approximate. The value of $k_{\text {dff }}$ for small cores such as those discussed in this report are generally overestimated. Salient differences between the ORNL and ANL approaches are given below.

$\begin{array}{lcc}\text { Parameter } & \text { VENTURE } & \text { REBUS } \\ \text { Number of groups } & 4 & - \\ \text { Number of burnup zones } & 299 & 9 \\ \text { Light water contamination } & - & .25 \%\end{array}$

The uncertainties implicit in the last two differences also were investigated.

Calculated values of $\mathbf{k}_{\mathrm{eff}}$ for the three cores are shown on Tables 3.2-3.4, in which the control rods are assumed to be withdrawn, and the reflector components are not included. Table 3.2 details the uncertainty associated with light water contamination, and the number of burnup zones.

Table 3.2 - Results for Two-Element Core (67.6 L)

\begin{tabular}{|c|c|c|c|c|c|}
\hline $\begin{array}{c}\text { Burnup period } \\
\text { (days) }\end{array}$ & $299 \mathrm{Z} * / \mathrm{NoH}_{2} \mathrm{O}$ & $\begin{array}{l}\text { VENTURE } \\
9 \mathrm{Z} / \mathrm{NoH}_{2} \mathrm{O}\end{array}$ & $9 \mathrm{Z} / 0.25 \% \mathrm{H}_{2} \mathrm{O}$ & REBUS & ANL-MCNP \\
\hline 0.0 & 1.3322 & 1.3358 & 1.3190 & 1.2927 & 1.2800 \\
\hline 8.5 & 1.1871 & 1.1948 & 1.1794 & 1.1618 & - \\
\hline 17.0 & 1.1124 & 1.1249 & 1.1098 & 1.0981 & 1.0945 \\
\hline 25.5 & 1.0248 & 1.0423 & 1.0278 & - & - \\
\hline
\end{tabular}

* $\mathrm{Z}$ indicates the number of burnup zones used in the calculation. 
Table 3.3 - Results for Three-Element Core (82.6 L)

\begin{tabular}{|c|c|c|c|}
\hline $\begin{array}{c}\text { Burnup period } \\
\text { (days) }\end{array}$ & VENTURE & REBUS & ANL-MCNP \\
\hline 0.0 & 1.2761 & 1.2352 & 1.2234 \\
\hline 8.5 & 1.1471 & 1.1164 & - \\
\hline 17.0 & 1.0876 & 1.0620 & 1.0492 \\
\hline 25.5 & 1.0209 & 1.0014 & - \\
\hline
\end{tabular}

Table 3.4 - Results for Three-Element Core (108 L)

\begin{tabular}{|c|c|c|c|}
\hline $\begin{array}{c}\text { Burnup period } \\
\text { (days) }\end{array}$ & VENTURE & REBUS & ANL-MCNP \\
\hline 0.0 & 1.2361 & 1.2204 & 1.2056 \\
\hline 8.5 & 1.1134 & 1.1070 & - \\
\hline 17.0 & 1.0598 & 1.0570 & 1.0492 \\
\hline 25.5 & 1.0033 & 1.0044 & - \\
\hline
\end{tabular}


Table 3.2 indicates that decreasing the number of burnup zones from 299 to 9 in the two-element core introduces a progressive deviation in $\mathbf{k}_{\text {eff }}$ which varies from essentially zero at $\mathrm{BOC}$ to approximately $2 \%$ at EOC. Furthermore, the addition of light water contamination to the core decreases $k_{\text {eff }}$ by approximately $1.5 \%$, regardless of burnup. Thus, compensating errors are introduced as a result of these two assumptions.

The agreement between VENTURE and REBUS is sufficiently close for the scope of the analyses carried out. This correspondence is an assurance that the physics calculations were done properly, with appropriate input data, and correct code implementation.

These calculational methods are most appropriate at this stage of the ANS design. As the design matures and additional details become specified, a more accurate study will be required, precisely presenting the core and using more sophisticated design methods.

Appendix 5 has the correspondence on quality assurance in the form of questions to ORNL from ANL, and the responses.

\subsection{RESULTS OF ANALYSES}

The method of analysis described in Section 3.1 was applied to the 19 cases on Table 3.1, Section 3.2. These results are presented on Table 3.5, which shows the peak flux in the moderator for each case. The fluxes were calculated by multiplying the peak flux determined during the burn-up cycle (using the VENTURE code system) by the ratio of the peak fluxes determined by VENTURE (diffusion theory) and MCNP (transport theory) at the beginning of cycle (BOC). Thus, the transport effects, which are important in a high leakage cores, such as the ANS designs, can be accounted for approximately. This adjustment can be made using either unperturbed fluxes (not including the effect of the beam tubes in the reflector) or perturbed (including them) fluxes. Both methods are shown on Table 3.5; the more representative method is that using unperturbed fluxes. Explanatory letter reports from ORNL, in Appendix 8, discuss these adjustments. The results shown in Table 3.5 show both values of peak flux; there is a significant difference depending on method of adjustment in selected cases. 
Table 3.5 - Results of Flux Calculations

\begin{tabular}{|c|c|c|c|c|c|c|c|c|}
\hline Case & $\begin{array}{l}\text { Element } \\
\text { Number }\end{array}$ & $\begin{array}{l}\text { Enrichment } \\
(\%)\end{array}$ & $\begin{array}{l}\text { Power } \\
\text { (MW) }\end{array}$ & $\begin{array}{l}\text { Uranium } \\
\text { Mass } \\
\text { (kg) }\end{array}$ & $\begin{array}{c}\text { Fuel } \\
\text { Density } \\
\text { (gU/cc) }\end{array}$ & $\begin{array}{c}\text { Peak }^{1} \\
\text { Flux } \\
\left(\mathrm{n} / \mathrm{m}^{2}-\mathrm{s}\right) \\
\mathrm{x} 10 \mathrm{E} 19\end{array}$ & $\begin{array}{c}\text { Peak }^{2} \\
\text { Flux } \\
\left(\mathrm{n} / \mathrm{m}^{2}-\mathrm{s}\right) \\
\mathrm{x} 10 \mathrm{E} 19\end{array}$ & $\begin{array}{c}\text { Peak }^{3} \\
\text { Flux } \\
\left(\mathrm{n} / \mathrm{m}^{2}-\mathrm{s}\right) \\
\mathrm{x} 10 \mathrm{E} 19\end{array}$ \\
\hline $\begin{array}{l}1 \\
2 \\
3 \\
4 \\
5\end{array}$ & $\begin{array}{l}2 \\
2 \\
3 \\
3 \\
3 \\
\end{array}$ & $\begin{array}{l}93 \\
80 \\
50 \\
50 \\
35\end{array}$ & $\begin{array}{l}330 \\
330 \\
330 \\
400 \\
405 \\
\end{array}$ & $\begin{array}{l}25.4 \\
31.4 \\
39.0 \\
42.8 \\
68.1 \\
\end{array}$ & $\begin{array}{l}1.7 \\
2.1 \\
2.0 \\
2.2 \\
3.5\end{array}$ & $\begin{array}{l}7.33 \\
7.25 \\
5.87 \\
7.06 \\
6.80 \\
\end{array}$ & $\begin{array}{l}7.55 \\
7.72 \\
6.50 \\
7.75 \\
6.96 \\
\end{array}$ & $\begin{array}{l}6.92 \\
6.90 \\
5.20 \\
6.19 \\
5.71 \\
\end{array}$ \\
\hline $\begin{array}{c}6 \\
7 \\
8 \\
9 \\
10\end{array}$ & $\begin{array}{l}3 \\
3 l \\
3 l \\
3 \\
3 l\end{array}$ & $\begin{array}{l}35 \\
20 \\
20 \\
20 \\
20\end{array}$ & $\begin{array}{l}330 \\
530 \\
449 \\
125 \\
330\end{array}$ & $\begin{array}{r}58.3 \\
193.6 \\
161.1 \\
68.1 \\
129.0\end{array}$ & $\begin{array}{l}3.0 \\
7.2 \\
6.0 \\
3.5 \\
4.8\end{array}$ & $\begin{array}{l}5.71 \\
7.12 \\
6.04 \\
2.17 \\
4.79\end{array}$ & $\begin{array}{l}6.24 \\
7.12 \\
6.04 \\
2.08 \\
4.79\end{array}$ & $\begin{array}{l}5.09 \\
6.16 \\
\text { N/A } \\
2.03 \\
4.14\end{array}$ \\
\hline $\begin{array}{l}11 \\
12 \\
13 \\
14 \\
15\end{array}$ & $\begin{array}{l}2 \\
3 \\
3 \\
3 l \\
3\end{array}$ & $\begin{array}{l}35 \\
50 \\
35 \\
20 \\
93\end{array}$ & $\begin{array}{l}330 \\
340 \\
370 \\
430 \\
330\end{array}$ & $\begin{array}{r}97.1 \\
39.0 \\
64.3 \\
156.0 \\
18.5\end{array}$ & $\begin{array}{l}6.5 \\
2.0 \\
3.3 \\
5.8 \\
1.0\end{array}$ & $\begin{array}{l}6.63 \\
5.98 \\
6.24 \\
6.00 \\
6.04\end{array}$ & $\begin{array}{l}6.61 \\
6.69 \\
6.52 \\
6.00 \\
\text { N/A }\end{array}$ & $\begin{array}{l}6.34 \\
5.34 \\
5.55 \\
5.17 \\
\text { N/A }\end{array}$ \\
\hline $\begin{array}{l}16 \\
17 \\
18 \\
19\end{array}$ & $\begin{array}{l}2 \\
3 \\
3 \\
3 l\end{array}$ & $\begin{array}{l}45 \\
45 \\
35 \\
35\end{array}$ & $\begin{array}{l}200 \\
250 \\
200 \\
260\end{array}$ & $\begin{array}{l}52.2 \\
35.1 \\
40.9 \\
48.4\end{array}$ & $\begin{array}{l}3.5 \\
1.8 \\
2.1 \\
1.8\end{array}$ & $\begin{array}{l}4.35 \\
4.68 \\
3.78 \\
3.99\end{array}$ & $\begin{array}{l}4.38 \\
4.38 \\
3.47 \\
3.93\end{array}$ & $\begin{array}{l}\text { N/A } \\
\text { N/A } \\
\text { N/A } \\
\text { N/A }\end{array}$ \\
\hline
\end{tabular}

1 Adjusted by using unperturbed flux ratios to determine cycle effects.

2 Adjusted by using perturbed flux ratios to determine cycle effects.

3 Average monthly flux at beam tube.

$* 3 \ell=3-\mathrm{L}$ element large core $(108 \mathrm{~L})$.

All the above cases satisfy the 17-day cycle time constraint, and the power density is less than, or equal to, that of the baseline design. However, several other constraints were not taken into account in the above comparison. Two of the more important ones are the heat loading on the cryogenic refrigerators of the cold sources, and fuel temperatures due to low thermal conductivity. The first constraint will affect reactor designs which have power levels much above that of the baseline design; the second will affect designs with high fuel densities. The imposition of these two additional constraints possibly will reduce the list of reactor designs in Table 3.5. The two methods of computing the peak flux show that the difference depends on the core's design. In selected cases, the 
difference is quite significant; however, the overall trends of the results remain unchanged. Additional methods have been proposed for measuring the relative flux performance of the various cores. Two such measures include a peak cycle average flux, and flux averaged over the location of the beam tube's mouth. These measures are included in Appendix 8. Based on cycle-averaged fluxes, the HEU core performs better than the LEU and MEU cores. The last column on Table 3.3 shows the flux averaged over the cycle, at the location of the beam tubes and cold sources. These values are of greatest interest to the user community. In general, the ratio of these fluxes to the baseline cases are below the corresponding ratios for the peak fluxes shown on either of the other two flux columns. Thus, in making decisions based on performance, a potential reduction ( $1 \%-10 \%)$ in useful flux should be accounted for.

Finally, the sensitivity of fuel density to changes in reactivity was estimated. An arbitrary reduction of $3 \%$ in reactivity requirements was made for two cases (Table 3.1), one HEU and the other LEU, and the impact on the fuel density determined; the two cases were the baseline case ( $93 \%$ enriched), and case 7 ( $20 \%$ enriched). In both cases, a $k_{\text {fff }}$ of 0.97 rather than 1.0 was maintained for the 17 -day cycle. In the baseline case, the required uranium loading was $21.6 \mathrm{~kg}$, corresponding to a fuel density of $1.45 \mathrm{gU} / \mathrm{cc}$ (a decrease of $15 \%$ ). The $20 \%$ enriched case went from a uranium density of 7.2 $\mathrm{gU} / \mathrm{cc}$ to a density of $6.1 \mathrm{gU} / \mathrm{cc}$, also a decrease of $15 \%$. This result is consistent with the experience of the RERTR programs (Appendix 9).

The above results can be summarized by arranging the various cases on a grid with fuel density along one axis, and core volume along the other (Table 3.6). In general, fuel enrichment decreases with increasing density. Furthermore, the ability to achieve a critical reactor design that will operate for the entire 17-day cycle requires progressively larger core volumes, and/or higher fuel densities as enrichment decreases. Thus, for a 2-element reactor, $93 \%$ enriched fuel requires a density of 1.7 $\mathrm{gU} / \mathrm{cc}$, and when the enrichment is dropped to $35 \%$, the density is required to increase to $6.5 \mathrm{gU} / \mathrm{cc}$. Similarly, only the largest reactor design (108 L) approaches the baseline design flux level using $20 \%$ enriched uranium, to achieve this goal requires a fuel density of $7.2 \mathrm{gU} / \mathrm{cc}$. This result implies that cores with a smaller volume would not achieve the desired goal at this enrichment level unless much higher density fuels were used. Even unrealistically high density cores may not necessarily achieve the performance goal, because increasing the density results in a "blacker" core which tends to defeat the notion of a high leakage core required for this type of reactor design. Eventually, a density will be reached when no increase in moderator flux will be achieved with increasing fuel density.

The results in Table 3.5 can be presented graphically by plotting relative flux against (power) (1/3 $^{1 / 3}$ (power density) $^{2 / 3}$. Figure 3.6 shows this variation for cores which have a 17-day cycle, and power densities below 4.9 MW/L. Selected case numbers from Table 3.5 also are shown in Figure 3.6. The baseline case is represented by a relative flux of 1.0 , and a value of $(P)^{1 / 3}(\rho)^{2 / 3}$ of 20.0 . The remaining cores all fall on straight lines, characteristic of their enrichment. The slope of these straight lines is approximately the same, regardless of enrichment, and the value of relative flux increases with $(P)^{1 / 3}$ $(\rho)^{2 / 3}$. Existing high flux reactors would be located in the bottom left-hand corner of the plot.

Figure 3.7 depicts the variation of maximum relative flux with enrichment for cores with fuel densities equal to, or less than $3.5 \mathrm{gU} / \mathrm{cc}$, and a cycle length of 17-days. Case numbers for the five cores 
corresponding to the five enrichment values investigated also are shown. The fuel density limit of 3.5 $\mathrm{gU} / \mathrm{cc}$ is based on the recommendations of the expert fuel panel. This curve illustrates the reduction in flux with decreasing enrichment using both 2- and 3-element cores. The top four points all operate at approximately the same power density. Thus, the 3-element cores are operating at high power levels and would require denser fuel to have sufficient ${ }^{233} \mathrm{U}$ to achieve a 17-day cycle. The result of $20 \%$ enrichment has a low power level, and hence, lower power density, implying lower performance. The requirements imposed by the fuel density and cycle-time limits are responsible for this designs lower operating power. Higher fuel densities, which are unlikely to be developed successfully, could allow the reactor to operate at higher powers and power densities, and thus improve performance.

A detailed analysis of fluid dynamics and heat transfer was made only for the baseline core. Thus, the thermal behavior of the other cores can only be estimated. The parameters of primary concern in such an analysis are the aluminum clad (Type 6061) and the fuel's centerline temperature, and the overall mechanical stability of the fuel plate. All these parameters are interrelated, since the temperature of the fuel plate depends on the power density and is inversely proportional to the heat conduction within the plate and the heat transfer from its surface. The temperatures are a function of the conductivities, while heat transfer depends on coolant's temperature and velocity. Finally, the build-up of aluminum oxide on the plates' surfaces, which acts as a thermal insulator, will affect the plates' temperature.

The reactor elements are designed so that the maximum power density occurs at the beginning of cycle (BOC) and at the coolant inlet. The highest centerline temperatures are expected at these locations close to BOC, and they decrease in magnitude, and move to the element's mid-plane as the cycle progresses. This shift is due to the consumption of fissile material with time. The oxide layer builds up as the cycle progresses, and tends to cause the temperature to increase with time following the initial decrease.

The parameters which affect the plates' mechanical stability are span length, curvature, and operating temperature. Curved plates are mechanically much more stable than flat plates of the same span length. Those plates associated with the small, inner element can have a larger span $(66 \mathrm{~mm})$, while still maintaining an acceptable curvature. However, as the element's radius increases, the change in span length should decrease to account for the decrease in plate curvature. This variation is characteristic of the involute plate shape. Figure 3.2 shows the span lengths for the small threeelement core varying from $66 \mathrm{~mm}-55 \mathrm{~mm}-44 \mathrm{~mm}$ for the three elements. In contrast, the large threeelement core studied has constant span lengths for all three elements $(66 \mathrm{~mm})$, and therefore, the curvature decreases for the two larger radius elements, with minimal curvature in the outermost element.

The overall mechanical stability of the plates is a combination of the mechanical and coolant-induced loads, the plate's curvature, span length, and the operating temperature. If the clad operating temperature exceeds $150^{\circ} \mathrm{C}$ (overaging temperature limit for $6061 \mathrm{Al}$ ) the clad can be expected to soften. Thus, it is important to design the plates with sufficient curvature to ensure mechanical stability at all operating temperatures. 
An attempt was made to estimate the change in peak fuel temperature from the baseline value for the reactor configurations discussed above. To undertake this analysis, the following assumptions were made:

1. An acceptable fuel grading can be achieved in all core designs, and the hot spot heat flux will scale with the average power density.

2. The limiting temperature is assumed to occur within the first third of the fuel cycle; this has been the experience to date, and is used to determine the conductivity of the fuel and the thickness of the oxide.

3. Thermal conductivities are obtained from data supplied by ANL at densities of 1.3 $\mathrm{gU} / \mathrm{cc}, 3.5 \mathrm{gU} / \mathrm{cc}, 4.8 \mathrm{gU} / \mathrm{cc}$, and $6.5 \mathrm{gU} / \mathrm{cc}$. The actual values used were obtained by interpolating between these values.

4. In all cases, the coolant velocity was assumed to be $25 \mathrm{~m} / \mathrm{s}$, thus implying the same heat-transfer coefficient in all cases.

5. Temperature drop through the fuel "meat" was assumed to vary directly with the heat flux, and inversely with its thermal conductivity. The temperature across the oxide film was assumed to vary directly with the heat flux and the film's thickness. All other temperature drops were assumed to vary directly with the heat flux.

Table 3.7 summarizes the analyses described above, and shows the change in temperature from the baseline case. In general, the results fall into the following four groups.

1. The first group includes cases $1,2,4$, and 5 which have a small change in both thermal conductivity and power density from the baseline case and show a small deviation in centerline temperature from the baseline case $\left(290^{\circ} \mathrm{C}\right)$.

2. The second group includes cases $3,6,9,12,13,15,16,17,18$, and 19 with a relatively high thermal conductivity coupled with a significant decrease in power density, and a significant decrease in temperature over the baseline case.

3. The third group has one case, number 10 , which has a low thermal conductivity (less than half the baseline value) and an reduced power density. It shows a reduction in peak fuel temperature of approximately $90^{\circ} \mathrm{C}$.

4. Finally, the fourth group, $(7,8,11$, and 14) includes those cases with a substantially reduced thermal conductivity, and power densities slightly below or equal to those of the baseline case. In all cases, there are significant increases in the fuel's temperature, generally into the unacceptable range. 
Table 3.6 - Summary of Calculational Case

\begin{tabular}{|c|c|c|c|}
\hline $\begin{array}{c}\text { Core Volume } \\
(\mathbf{L}) \\
\end{array}$ & \multicolumn{3}{|c|}{$\begin{array}{c}\text { Fuel Density } \\
\text { (gU/cc) }\end{array}$} \\
\hline & $1.7-3.5$ & $3.5-6.0$ & $>6.0$ \\
\hline 67.6 & $\begin{array}{c}\text { HEU } \\
\text { Cases } 1 \text { and } 2 \\
\end{array}$ & $\begin{array}{c}\text { HEU/MEU } \\
\text { Case } 16\end{array}$ & $\begin{array}{c}\text { MEU } \\
\text { Case } 11 \\
\end{array}$ \\
\hline 82.6 & $\begin{array}{c}\text { HEU/MEU } \\
\text { Cases } 3,4,6,12, \\
17 \text {, and } 18 \\
\end{array}$ & $\begin{array}{l}\text { MEU/LEU } \\
\text { Cases } 5 \text { and } 9\end{array}$ & $\begin{array}{c}\text { LEU } \\
-\end{array}$ \\
\hline 108.0 & $\begin{array}{c}\text { MEU } \\
\text { Case } 19\end{array}$ & $\begin{array}{c}\text { LEU } \\
\text { Case } 10\end{array}$ & $\begin{array}{c}\text { LEU } \\
\text { Case } 7 \text { and } 8\end{array}$ \\
\hline
\end{tabular}


Table 3.7 - Summary of Estimates of Peak Fuel Centerline Temperature

\begin{tabular}{|c|c|c|c|c|c|}
\hline $\begin{array}{l}\text { Case } \\
\text { No. }\end{array}$ & $\begin{array}{c}\text { Fuel } \\
\text { Density } \\
(\mathrm{gU} / \mathrm{cc})\end{array}$ & $\begin{array}{l}\text { Fuel Meat } \\
\text { Thermal } \\
\text { Conductivity } \\
\left(\mathrm{W}-\mathrm{m}^{-1}-\mathrm{K}^{-1}\right)\end{array}$ & $\begin{array}{l}\text { Average } \\
\text { Power } \\
\text { Density } \\
(\mathrm{MW} / \mathrm{L})\end{array}$ & $\begin{array}{c}\text { Estimated } \\
\text { Change in Peak } \\
\text { Fuel Centerline } \\
\text { Temp. } \\
\left({ }^{\circ} \mathrm{C}\right) \\
\end{array}$ & Comments \\
\hline 1 & 1.7 & 158 & 4.88 & Reference Case & $\begin{array}{l}\text { Peak fuel temperature for the } \\
\text { reference case has been } \\
\text { determined to be } 290^{\circ} \mathrm{C} \text { using } \\
\text { a detailed analysis approach. }\end{array}$ \\
\hline 2 & 2.1 & 143 & 4.88 & +2 & \\
\hline 3 & 2.0 & 146 & 4.00 & -70 & \\
\hline 4 & 2.2 & 141 & 4.84 & -2 & \\
\hline 5 & 3.5 & 105 & 4.90 & +13 & \\
\hline 6 & 3.0 & 119 & 4.00 & -60 & \\
\hline 7 & 7.2 & 10 & 4.9 & Estimate N/A & Well beyond allowable limit. \\
\hline 8 & 6.0 & 15 & 4.16 & +110 & $\begin{array}{l}\text { Previously calculated with } \\
\text { more detailed analysis. }\end{array}$ \\
\hline 9 & 3.5 & 105 & 1.51 & -180 & \\
\hline 10 & 4.8 & 55 & 3.06 & -90 & \\
\hline 11 & 6.5 & 10 & 4.88 & +310 & $\begin{array}{l}\text { Well beyond the allowable } \\
\text { range at } 600^{\circ} \mathrm{C} \text {. Estimate } \\
\text { that maximum power for this } \\
\text { density might be around } \\
200 \mathrm{MW} \text {. }\end{array}$ \\
\hline 12 & 2.0 & 146 & 4.00 & -70 & \\
\hline 13 & 3.3 & 110 & 4.48 & -30 & \\
\hline 14 & 5.8 & 20 & 3.98 & $\begin{array}{r}+50 \\
\end{array}$ & \\
\hline 15 & 1.0 & 165 & 4.00 & -70 & \\
\hline 16 & 3.5 & 105 & 2.96 & -115 & \\
\hline 17 & 1.8 & 152 & 3.03 & -120 & \\
\hline 18 & 2.1 & 143 & 2.42 & -145 & \\
\hline 19 & 1.8 & 152 & 2.41 & -145 & \\
\hline
\end{tabular}

A detailed outline of the above discussion is presented in Appendix 10. 


\subsection{SUMMARY}

The following observations can be made:

1. The high enrichment cores ( $>80 \%$ ) all meet the requirements for flux performance, with a fuel density of less than, or equal to, $2.1 \mathrm{gU} / \mathrm{cc}$. These cases are represented by 1 and 2 . Furthermore, a higher fuel density could be detrimental in these cases. Finally, fuel fabrication and behavior is within the state-of-the-art at this density.

2. At an enrichment level of $50 \%$, the performance goal can be reached if the core volume is increased to $82.6 \mathrm{~L}$ and the power level is increased to $400 \mathrm{MW}$ (case 4). A reduction of the reactor power to the baseline value implies a reduction of $20 \%$ in the performance goal (case 3). The fuel density in both these cases is less than, or equal to, $2.2 \mathrm{gU} / \mathrm{cc}$, which is within the state-of-the-art.

3. A reduction of the enrichment to $35 \%$ requires that the volume of the core or the fuel's density is increased to high values. At a power of $330 \mathrm{MW}$, a reduction of $22 \%$ and $10 \%$ peak flux is implied for cases 6 and 11, respectively. Case 6 is the intermediate size core with a fuel density of $3.0 \mathrm{gU} / \mathrm{cc}$, and case 11 is the small core with a density of $6.5 \mathrm{gU} / \mathrm{cc}$. The reduction for case 6 can be reduced to $12 \%$ by increasing the reactor power to $405 \mathrm{MW}$ and the fuel density to $3.5 \mathrm{gU} / \mathrm{cc}$ (case 5). This is the highest power level for operating this volume core without violating the power density constraints.

4. A reduction of the enrichment to $20 \%$ requires a core volume of $82.6 \mathrm{~L}$, with a fuel density of $3.5 \mathrm{gU} / \mathrm{cc}$, and a power of $125 \mathrm{MW}$, implying a flux reduction of $70 \%$ (case 9 ). Attempting to maintain the flux performance goal requires the largest core volume considered in this study. At a fuel density of $6.0 \mathrm{gU} / \mathrm{cc}$ and an operating power of $449 \mathrm{MW}$, the flux level of this design is still lower than the baseline flux goal by $18 \%$ (case 8). At the baseline power level and a more moderate fuel density (case 10 ), the flux is reduced by $35 \%$. It is clear that lower enrichment fuels not only require the highest fuel densities but also the largest core volumes. Both these requirements imply a development effort above that planned for in the current design.

5. Estimates of peak fuel temperature indicate that all but four reactor designs yield potentially acceptable values. These acceptable values are due to either sufficiently high thermal conductivities due to low fuel densities or due to low power densities. However, this analysis is a preliminary one; a more detailed analysis is required to finalize these values. 


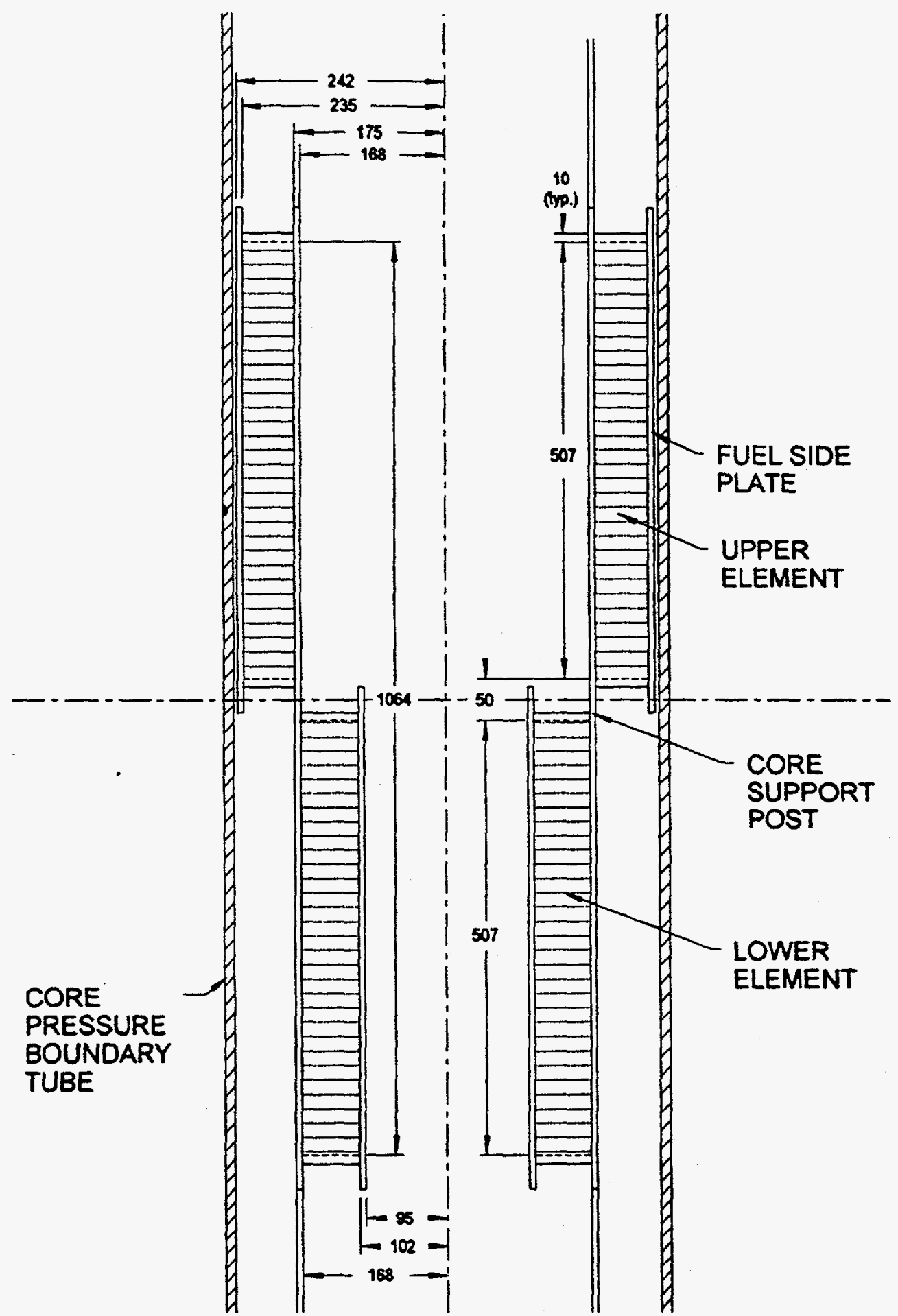

Figure 3.1 Dimensions of the Conceptual 2 Element Core Design (67.6 L) 


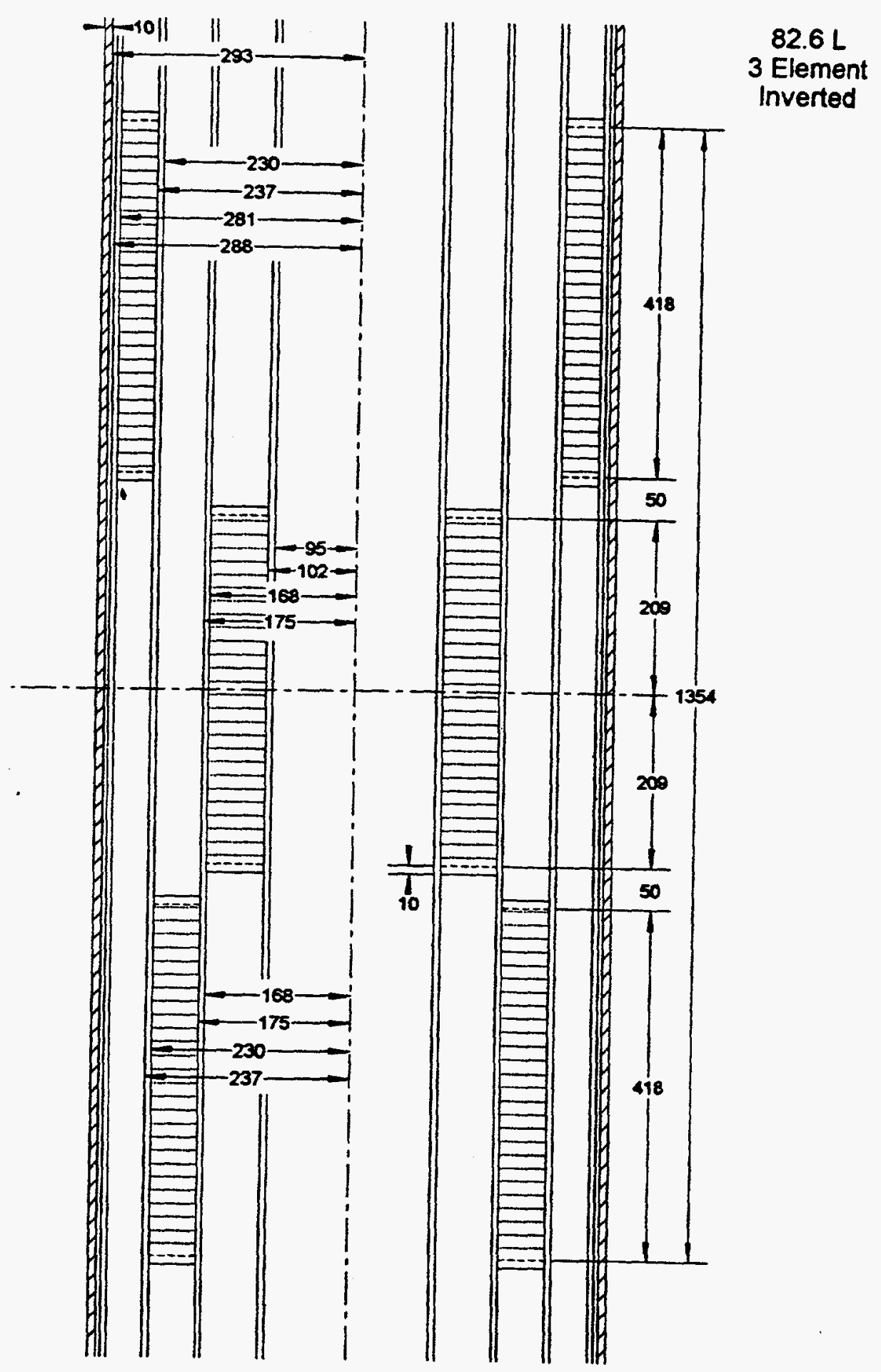

Figure 3.2 Dimensions of the Conceptual 3 Element Core Design (82.6 L) 


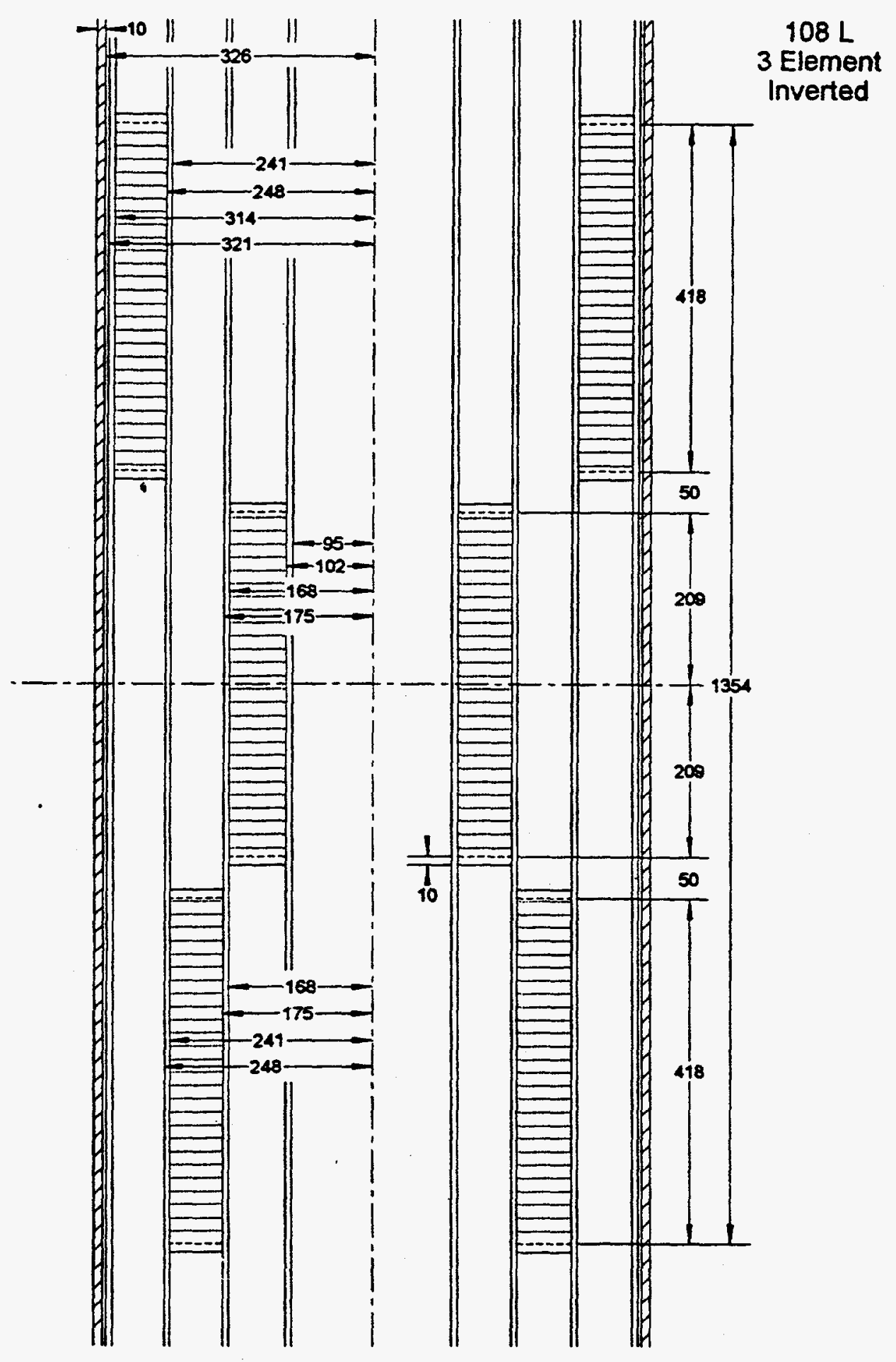

Figure 3.3 Dimensions of the Conceptual 3 Element Core Design (108 L) 


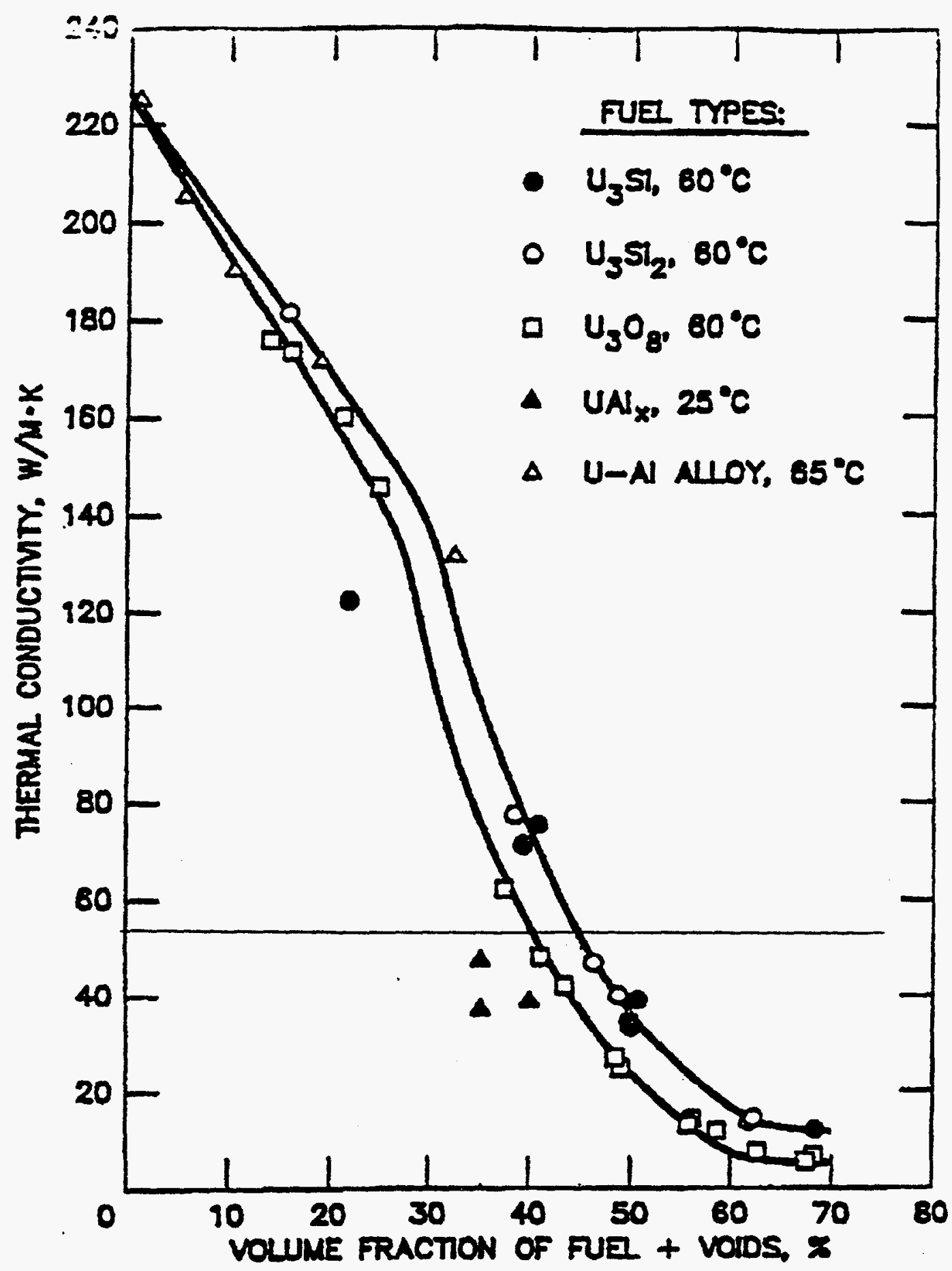

Figure 3.4 Thermal Conductivities of Candidate HWR-NPR Fuels as a Function of the Volume Fraction of Fuel + Voids 


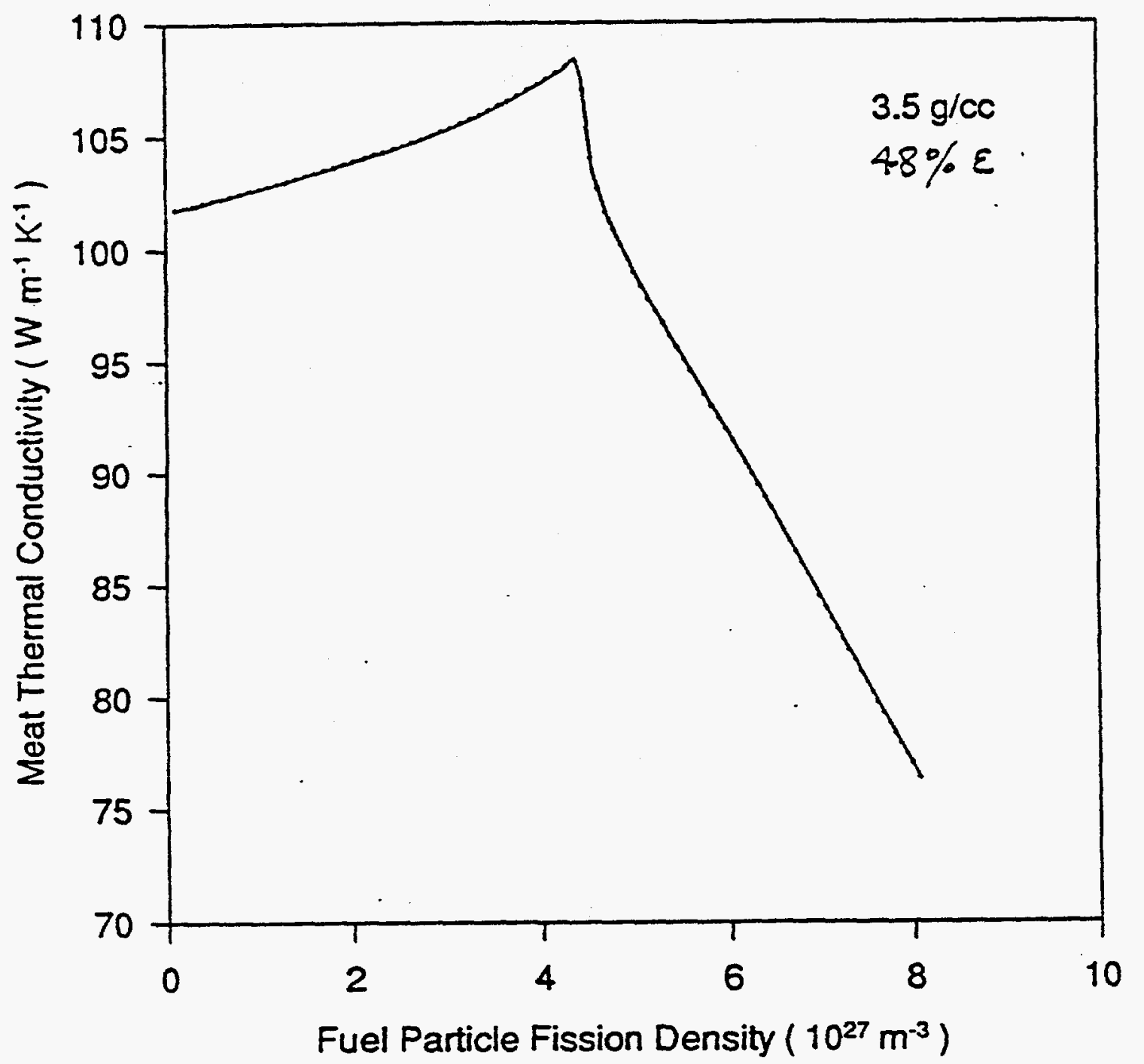

Figure 3.5 Variation of Fuel Conductivity with Burn-up 


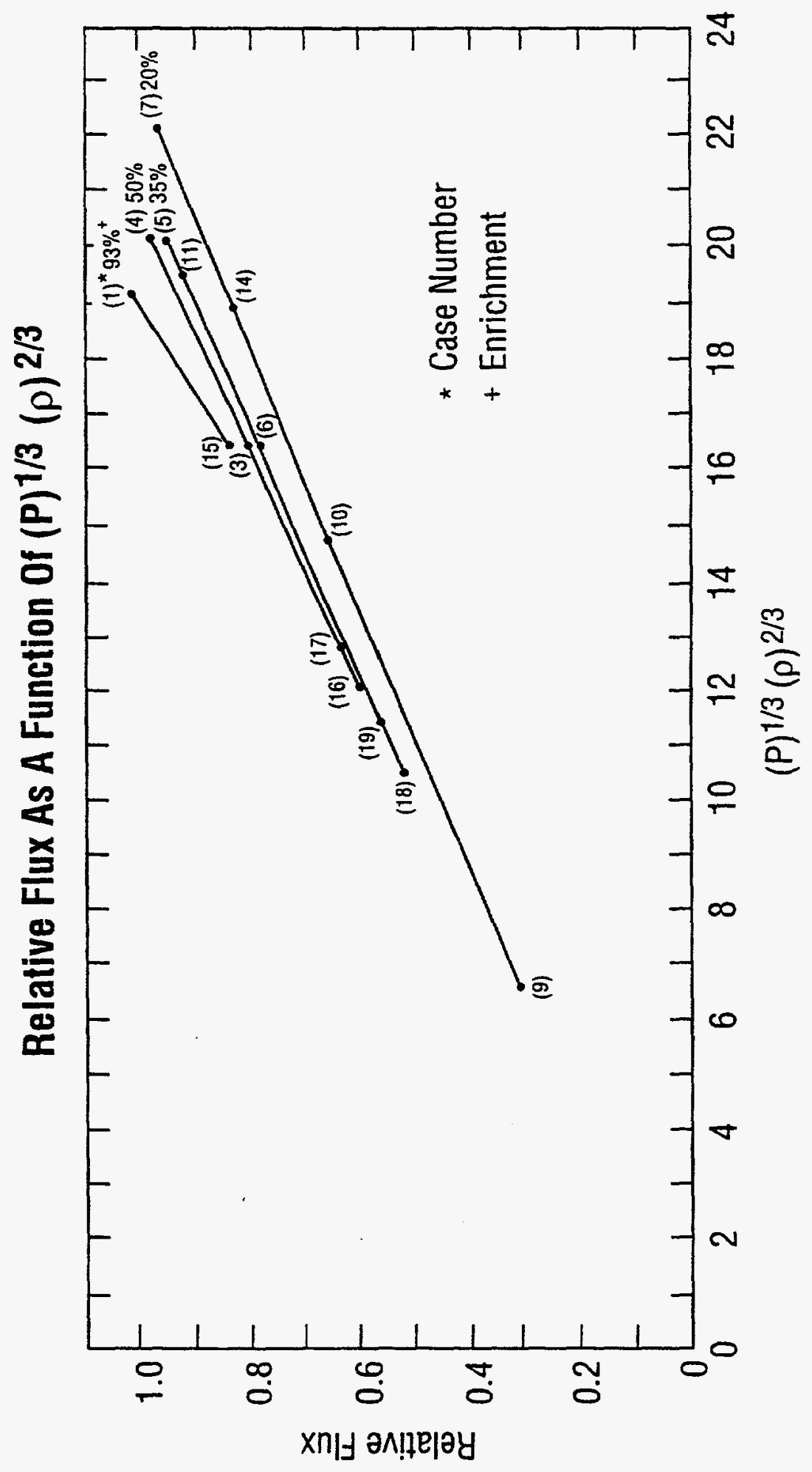

Figure 3.6 Relative Flux as a Function of $(P)^{1 / 3}(\rho)^{2 / 3}$ 


\section{Relative Flux As A Function Of Enrichment \\ (Fuel Density < 3.5 gm/cc)}

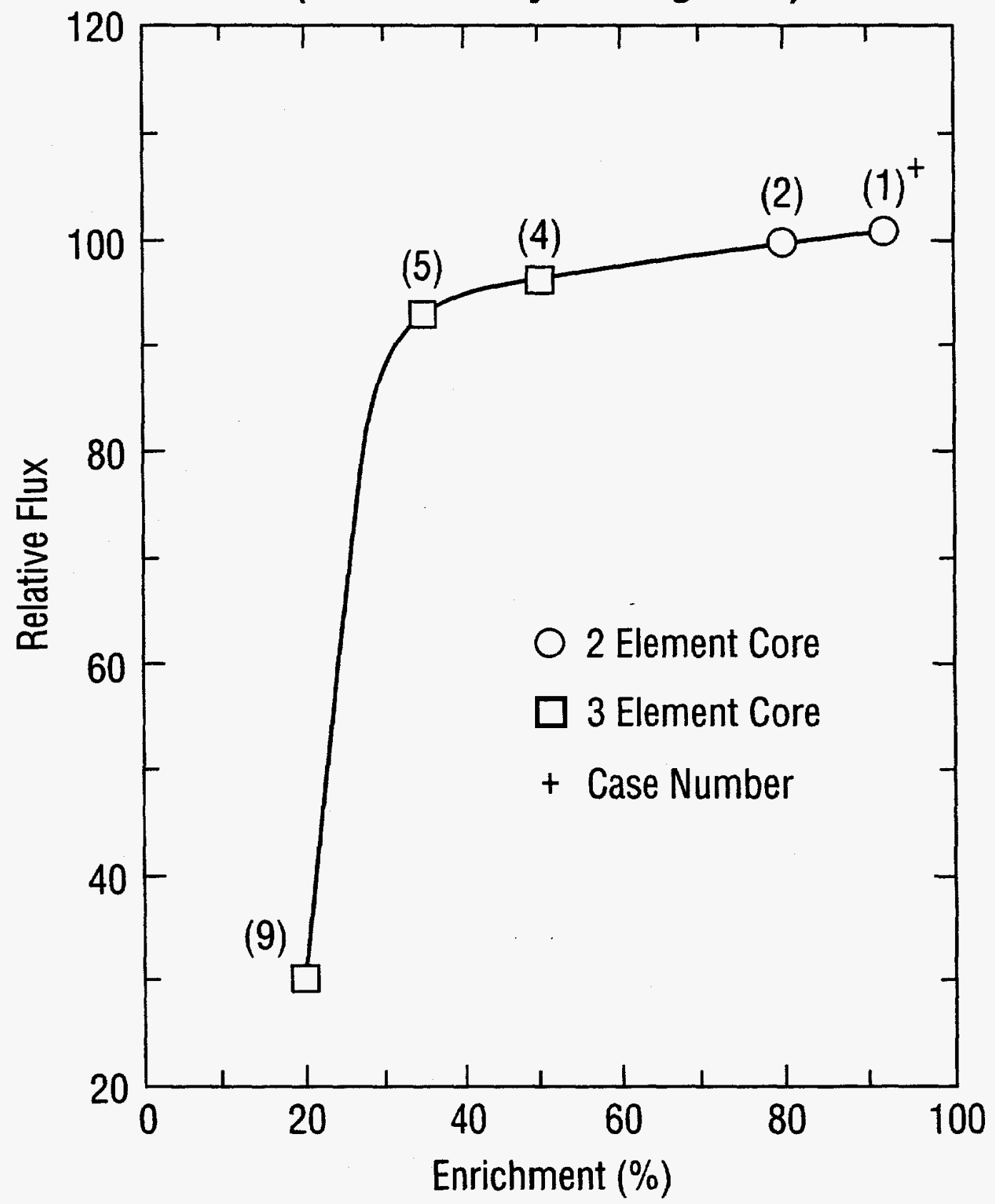

Figure 3.7 Relative Flux as a Function of Enrichment (Fuel Density $<3.5 \mathrm{gm} / \mathrm{cc}$ ) 



\subsection{EVALUATION OF THE FUEL EXPERTS PANEL}

\subsection{BACKGROUND}

The ANS-LEU Fuel Panel met at Brookhaven National Laboratory, December 14 and 15, 1993 to assess the feasibility of achieving higher density LEU fuels for the ANS. Appendix 11 lists the Attendees. On December 14, the Panel met with representatives of the ANS Project; the agenda for this meeting is included as Appendix 11, and the minutes of the meeting and handouts from the presentations are included as Appendices 13 through 21. On December 15, the Panel met in caucus to discuss the material presented the previous day and draft its recommendations.

\subsection{PANEL DISCUSSIONS}

There is no commercial fuel that can be compared with the ANS proposed designs: the gradients of the meat (lateral and longitudinal), power densities, heat flux, temperatures, dimensional tolerances, and percent burn-up each require extrapolations of known technology for fabrication, inspection, and irradiation performance, even for the HEU $1.7 \mathrm{gU} / \mathrm{cc}$ fuel being considered. Thus, even with this reference fuel loading, there are some performance uncertainties that the Panel believes may require a modest fuel-development program. All current high flux reactors use high enriched $(93 \%) \mathrm{UAl}_{\mathrm{x}}$ or $\mathrm{U}_{3} \mathrm{O}_{8}$ as the meat; ANS proposes to use $\mathrm{U}_{3} \mathrm{Si}$ because of its higher uranium density. In particular, the panel was concerned about fuel's performance if centerline temperatures approach the $400^{\circ} \mathrm{C}$ hot spot listed in the design parameters. It should be noted that the ANS project has considered reducing this temperature to $300^{\circ} \mathrm{C}-350^{\circ} \mathrm{C}$. Furthermore, the baseline core has a maximum temperature of approximately $300^{\circ} \mathrm{C}$.

The real difficulty in testing any ANS Fuel is obtaining the necessary power densities in existing reactors. As a minimum, miniature plates of the several possible fuel densities should be made and irradiated in the HFIR flux trap facility, followed by irradiations of test elements in the HFIR or ATR, and, finally, confirmation tests (at lower power densities) in the ANS itself.

The Panel believes it is feasible to go to lower enrichments and higher uranium loadings, but each such step would increase the size of the test program, reduce the probability of success and increase the manufacturing difficulty, and percent of rejected plates. The Panel attempted to quantify this conclusion, based on past experience with other fuel types and on the intuitive judgment of each individual member (Table 4.1). Yves Fanjas noted that, with techniques that are still proprietary, CERCA has rolled good quality flat plates, with no gradient requirements, at meat concentrations of 4.8 and $6.0 \mathrm{gU} / \mathrm{cc}$. However, $6.0 \mathrm{gU} / \mathrm{cc}$ must be counted as the maximum density achievable using conventional technology for making the plates. Higher densities will require developing new technologies for fuel-plate fabrication. His viewgraphs on the properties of this fuel are included in Appendix 19. 
Fanjas noted that there are no data on radiation performance for the CERCA $6 \mathrm{gU} / \mathrm{cc}$ fuel plates, and the $4.8 \mathrm{gU} / \mathrm{cc}$ plates were tested only in research reactors with much lower power densities (by factors of 10 or more) than those proposed in the ANS design. Thus, while it is very difficult to prove a cutoff fuel density for the ANS, the Panel adopted $6.0 \mathrm{gU} / \mathrm{cc}$ as an upper limit with current fabrication technologies. Given sufficient time $(\approx 10-20$ years) and money (greater than $\$ 100$ million), the Panel believes new technologies for fuels above $6.0 \mathrm{gU} / \mathrm{cc}$ may be developed, but the chance of success would not be high.

The Panel believes there is a good chance that fuels meeting the ANS requirements can be successfully produced, but is concerned about the difficulties in demonstrating the irradiation performance of any proposed fuel at high fluxes in existing facilities. Small pressed and/or punched plates may not contain fission gases, and, therefore, not address swelling of the fuel. The principal concerns are the temperature, swelling, corrosion, and warpage and fluttering of the plates, especially if wider plates of lower curvature are required, as in the $108 \mathrm{~L}$ core designs. Thus, the Panel does not recommend changing the basic fuel design, as would be required by the $108 \mathrm{~L}$ core, but suggests that using the 3-element $82.6 \mathrm{~L}$ core provides additional versatility over the 2-element design for testing advanced fuels and, possibly, lower enrichments once the ANS is operable.

The Panel also attempted to estimate uncertainties in fuel performance as a function of the uranium content of the meat (Table 4.2). The largest question relates to the thermal conductivities of the irradiated material and the accompanying effects of high meat temperature. Irradiation tends to lower thermal conductivity and cause reactions between the matrix and fuel. The Panel noted that, if the temperature of the cladding rises above about $150^{\circ} \mathrm{C}$, it may soften and, therefore, the fuel plate's rigidity might be lost, with potentially major consequences. During exposure in the ANS, the high heat-flux areas of the cladding may develop adherent oxides greater than 1 mil thick, which would form the principal thermal barrier. The temperature of the meat-cladding interface could become so high that the cladding will weaken. This situation is likely to occur if the fuel's centerline temperatures approach $400^{\circ} \mathrm{C}$ for low conductivity meat, or even $300^{\circ} \mathrm{C}$ for higher conductivity meat. The temperature distribution is schematically shown in Figure 4.1. The Panel recommends that the effects of this temperature distribution be examined for any fuel design of the ANS. Also, swelling of the fuel increases with temperature. If wider plates are required, as in the lowest enrichment cases, or the $108 \mathrm{~L}$ core, this softening could seriously complicate plate fluttering and flow instabilities.

The meat's centerline temperature depends on its thermal conductivity, for a given heat generation and coolant flow rate. Since the plate's surface temperature and oxide build up do not depend on the meat's thermal conductivity, the concern over cladding temperature is the same, whatever the composition of the meat. 
The Panel also noted that, for unirradiated meats, the thermal conductivity, strength, and ductility of the meat drop dramatically above about $3.5 \mathrm{gU} / \mathrm{cc}$. While the limited calculations and metallography of irradiated fuel (showing the growth of $\mathrm{U}_{\mathrm{x}} \mathrm{Al}_{\mathrm{y}} \mathrm{Si}_{\mathrm{z}}$ layers around the particles) suggest the low conductivity may be less of a concern at higher fuel densities, remaining uncertainties (including swelling at high temperatures and validation of the model for calculating thermal conductivity of irradiated fuel) suggest fuel development for densities greater than 3.5 $\mathrm{gU} / \mathrm{cc}$ would be a major effort, difficult to achieve because of the lack of test facilities; consequently, it should be deferred until the ANS itself is available. The Panel considered only the fuel density in its deliberations and left to the ANS project to consider the reduced enrichments made possible by the various loadings. A further discussion of the Panel's concerns on the effect of high temperature in the meat, and a suggested program to examine it can be found in Appendix 20, a memo to the Panel from panel member Richard Hobbins, dated 12/21/93.

Also, subsequently, Yves Fanjas wrote a memo, "Feasibility of ANS Plates with Reduced Enrichment U," which is included as Appendix 21.

Finally, the Panel considered the incremental costs and probability of success ${ }^{* *}$ associated with increasing the fuel loading above the current reference design of $1.7 \mathrm{gU} / \mathrm{cc}$, recognizing that some baseline demonstration program is required for the reference HEU fuel. The results are given in Table 4.3. Cost and time, while related, are not directly proportional; costs and time are given as related to the recommended baseline program, for which time is about 2 years, and costs are of the order of $\$ 10$ million. The probability of success also is normalized to the baseline design $(1.7 \mathrm{gU} / \mathrm{cc})$, for which the probability was assigned a value of unity. Figure 4.2 plots the estimates shown on Table 4.3.

\subsection{CONCLUSIONS}

1. The Panel believes that increasing the fuel density up to $3.5 \mathrm{gU} / \mathrm{cc}$, using the current fabrication technology and $\mathrm{U}_{3} \mathrm{Si}_{2}$ fuel particles, will stretch current technology, but probably will not add greatly to the costs nor decrease significantly the probability of success. Going to fuel loadings of $4.8 \mathrm{gU} / \mathrm{cc}$ and higher will introduce larger costs and uncertainties, and require a considerable development effort. Fuel loadings greater than $6.0 \mathrm{gU} / \mathrm{cc}$ will require a major development program, including developing and testing of new fabrication technologies, which have a low likelihood of success.

"The Panel defined "Probability of Success" as the probability that a fuel can be routinely fabricated to the ANS tolerances and design, and can be shown to meet its performance requirements. 
2. The Panel recommends using the three (3) element core $(82.6 \mathrm{~L})$ to provide versatility for testing advanced fuels, and possibly, lower enrichments once the ANS is operable.

3. There are some uncertainties about fabrication and performance associated with the HEU 1.7 $\mathrm{gU} / \mathrm{cc}$ fuel density currently being considered. The Panel recommends addressing these uncertainties in the fuel development program.

4. The high fuel temperature may soften cladding and cause a loss of the plate's strength and rigidity. This effect needs to be evaluated for all fuel designs. For this reason, the panel does not recommend adopting the wider plates with lower curvature (i.e., the $108 \mathrm{~L}$ core). 
Table 4.1 - Relative Manufacturing Difficulty

for Possible ANS Fuel Materials*

\begin{tabular}{|l|l|l|l|l|l|}
\hline \multirow{2}{*}{ Requirements } & \multicolumn{5}{c|}{ Fuel Density, gU/cc } \\
\cline { 2 - 6 } & 1.3 & 1.7 & 3.5 & 4.8 & 6.0 \\
\hline $\begin{array}{l}\text { Shape (taper, tolerances } \\
\text { of meat) }\end{array}$ & 4 & 4 & 5 & 6 & 7 \\
\hline Uranium homogeneity & 3 & 3 & 4 & 5 & 6 \\
\hline Minimum cladding thickness & 2 & 2 & 3 & 4 & 5 \\
\hline Non-bond (1 mm max)** & 2 & 2 & 3 & 4 & 5 \\
\hline Stray particles & 1 & 1 & 1 & 1 & 1 \\
\hline Plate length and width & 1 & 1 & 1 & 1 & 1 \\
\hline $\begin{array}{l}\text { Formability to desired } \\
\text { curvature }\end{array}$ & 1 & 1 & 1 & 1 & 2 \\
\hline Plate thickness & 1 & 1 & 1 & 1 & 1 \\
\hline Minimum end cladding & 3 & 3 & 3 & 4 & 4 \\
\hline Minimum edge cladding & 1 & 1 & 1 & 1 & 1 \\
\hline
\end{tabular}

* On a scale of 1 to 10 (10 being the greatest difficulty), using current rolling technology. Above $6.0 \mathrm{gU} / \mathrm{cc}$, new fabrication techniques must be developed.

** Related mainly to the inspection technique, which becomes increasingly difficult as the uranium density increases. 
Table 4.2 - Relative Concerns* About Fuel Performance in ANS

\begin{tabular}{|c|c|c|c|c|c|}
\hline \multirow{2}{*}{ Property of Fuel } & \multicolumn{5}{|c|}{ Fuel Density, gU/cc } \\
\hline & 1.3 & 1.7 & 3.5 & 4.8 & 6.0 \\
\hline $\begin{array}{l}\text { Thermal conductivity as } \\
\text { fabricated }\end{array}$ & 1 & 1 & 3 & 7 & 9 \\
\hline $\begin{array}{l}\text { Irradiation behavior } \\
<150^{\circ} \mathrm{C} \text { CLT } \\
200-250^{\circ} \mathrm{C} \text { CLT } \\
400^{\circ} \mathrm{CLT} \text { ? }\end{array}$ & $\begin{array}{l}1 \\
2 \\
7 \\
\end{array}$ & $\begin{array}{l}1 \\
2 \\
7\end{array}$ & $\begin{array}{l}1 \\
2 \\
7 \\
\end{array}$ & $\begin{array}{l}1 \\
3 \\
9 \\
\end{array}$ & $\begin{array}{l}2 \\
3 \\
9 \\
\end{array}$ \\
\hline $\begin{array}{l}\text { Thermal conductivity as } \\
\text { irradiated? }\end{array}$ & 2 & 2 & 3 & 8 & 10 \\
\hline Channel spacing stability & 1 & 1 & 1 & 2 & 2 \\
\hline
\end{tabular}

* on a scale of $1-10$, with 10 being the greatest concern

CLT: centerline (or hot spot) temperature

? means unknown property

Table 4.3 - Effect of Design Fuel Density on ANS Program

\begin{tabular}{|c|c|c|c|c|c|}
\hline \multirow{2}{*}{ Parameter } & \multicolumn{5}{|c|}{ Fuel Density, gU/cc } \\
\hline & -0.4 & 3.5 & 4.8 & 6.0 & $>6.0$ \\
\hline $\mathrm{R} \& \mathrm{D}$ costs, $\$ \times 10^{-7}$ & 1.0 & 1.2 & 2.0 & 2.5 & $>10$ \\
\hline $\begin{array}{l}R \& D \text { program time } \\
(T \approx 2 \text { years })\end{array}$ & $\mathrm{T}$ & $1.1 \mathrm{~T}$ & $2.0 \mathrm{~T}$ & $3.0 \mathrm{~T}$ & $>10 \mathrm{~T}$ \\
\hline Probability of success & 1 & 0.95 & 0.7 & 0.5 & $<0.1$ \\
\hline
\end{tabular}




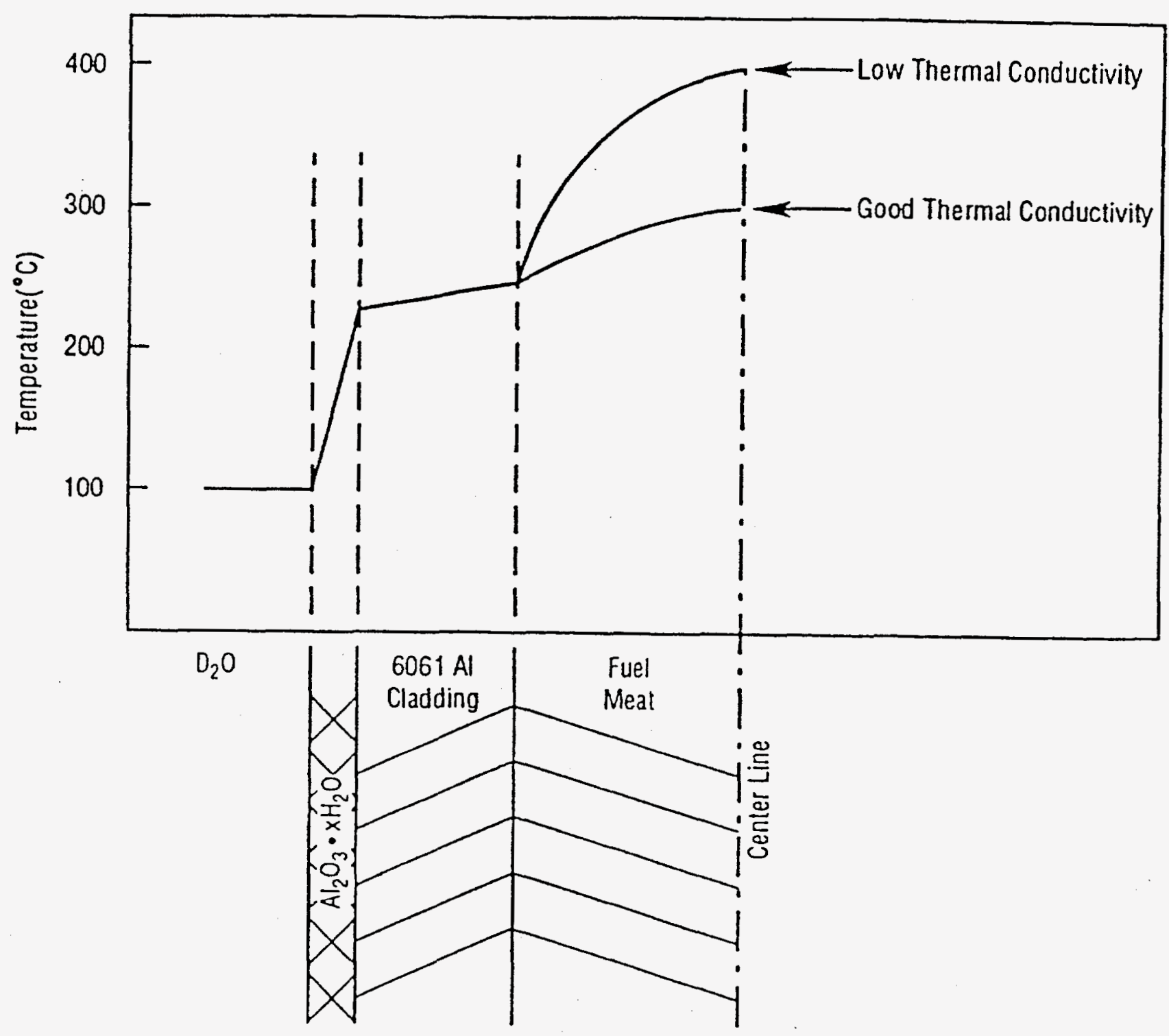

Figure 4.1 Hypothetical Temperature Profile of Concern (Cladding exceeds the soltening temperature (approximately $200^{\circ} \mathrm{C}$ ) of $6061 \mathrm{Al}$ ) 


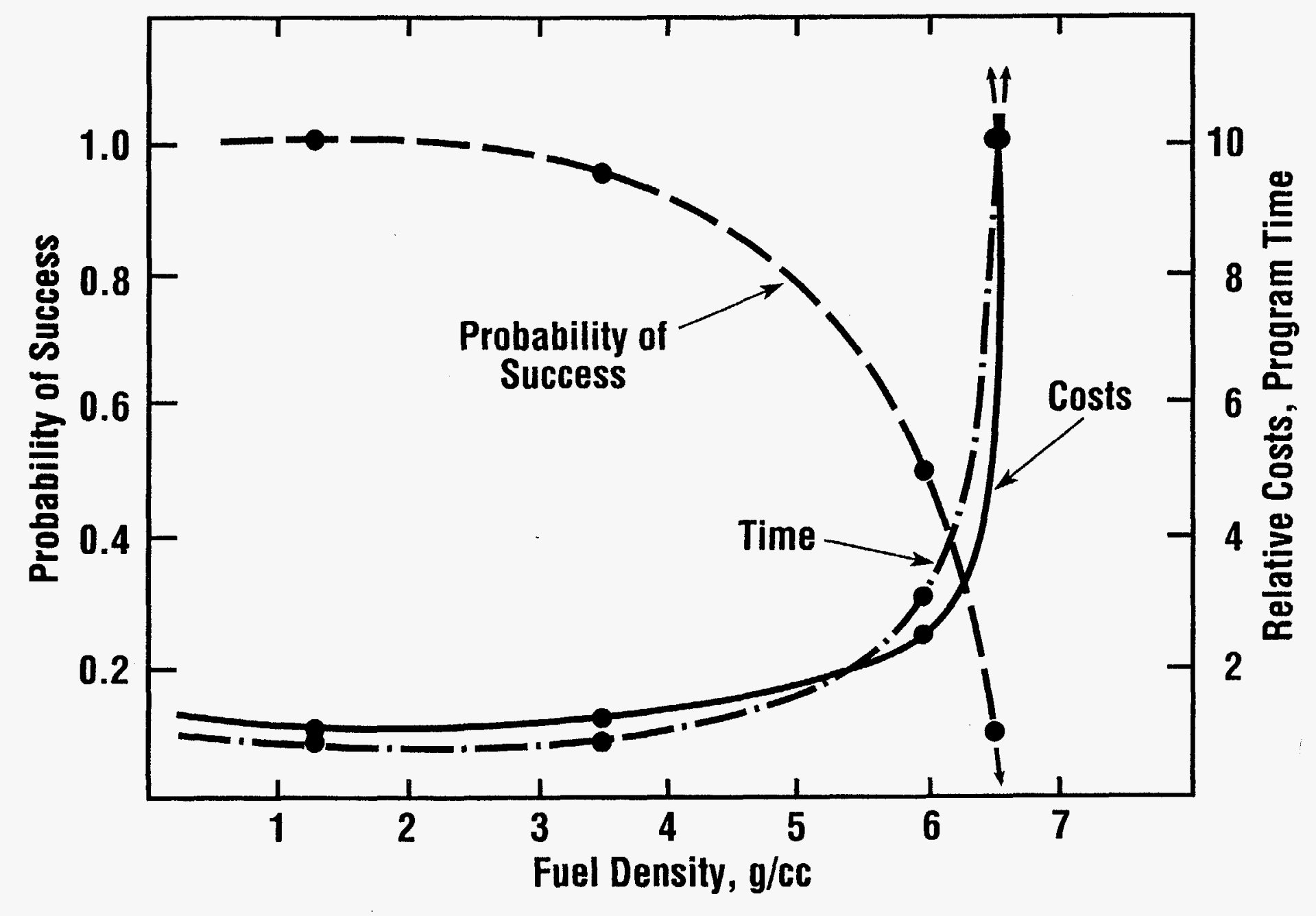

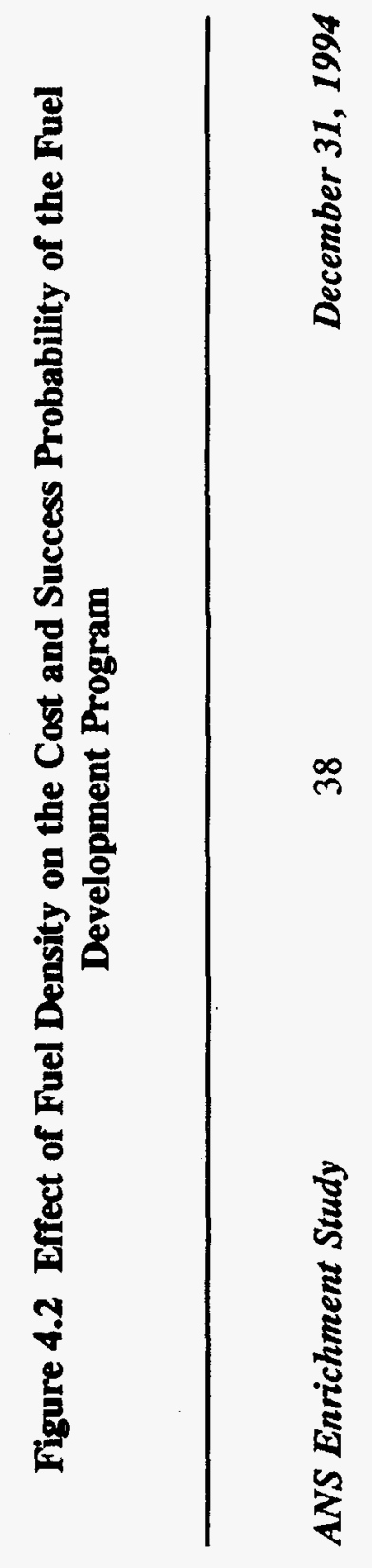




\subsection{ATTRIBUTE RATINGS}

In this section, the following measures of performance are discussed and compared for the various enrichments values used in the study.

1. The maximum thermal neutron flux in the reflector compared to the baseline goal,

2. The change in cost compared to the baseline design,

3. The safety implications of using lower enrichment fuel, and

4. Safeguards advantages of the lower enrichment fuel.

Table 5.1 summarizes the cost and flux comparisons. In addition, it shows the production of plutonium/year for the various cores.

The performance comparisons are discussed in more detail in the sections below. In particular, the dependence of flux and fuel density on enrichment are considered to be the primary measure of performance. Cost considerations are assumed to be composed of two parts (plant construction and operating); the total cost of any option then is measured by combining these two components. The enhanced production of plutonium for the reduced enrichment cases has implications for safety and safeguards.

\subsection{THERMAL NEUTRON FLUX}

In this section, the dependence of flux and fuel density on enrichment for various ANS designs will be explored. By comparing the above two results, the dependence of flux on fuel density also can be obtained. The results, in Table 5.1, show the following trends for reactors generating more than $330 \mathrm{MW}$.

1. Increases in power at an approximately constant fuel density and enrichment cause an increase in relative flux (case 4 vs. case 3 ).

2. Increases in both power and fuel density at the same enrichment and core size results in an increase in the flux (case 8 vs. case 10). However, flux per megawatt stays essentially constant.

3. Using low enrichment fuel in smaller cores implies operating at a lower power level to complete the 17-day cycle. This lower power level leads to a low flux (case 9 vs. case 5).

The following tables show the dependence of flux, fuel density, and cost on enrichment for the three reactor-core designs generating $330 \mathrm{MW}$.

Table 5.2 shows that the lowest enrichments are not feasible for the smallest designs, since the fuel density limits are reached. 
Table 5.1 - Comparisons of Performance for Various Cores

\begin{tabular}{|c|c|c|c|c|c|c|c|c|c|}
\hline Case & $\begin{array}{c}\text { Element } \\
\text { Number }\end{array}$ & $\begin{array}{c}\text { Power } \\
\text { (MW) }\end{array}$ & $\begin{array}{c}\text { Enrichment } \\
\text { (\%) }\end{array}$ & $\begin{array}{c}\text { Fuel } \\
\text { Density } \\
\text { (gU/cc) }\end{array}$ & $\begin{array}{c}\text { Relative } \\
\text { Flux }\end{array}$ & $\begin{array}{c}\text { TPC* } \\
\text { Penalty } \\
\text { \$M }\end{array}$ & $\begin{array}{c}\text { OC }^{*} \\
\text { Penalty } \\
\text { \$M }\end{array}$ & $\begin{array}{c}\text { Pu } \\
\text { Prod.\# } \\
\text { (kg/yr) }\end{array}$ & $\begin{array}{c}\text { DOE } \\
\text { Safeguards } \\
\text { Category }\end{array}$ \\
\hline \hline 1 & 2 & 330 & 93 & 1.7 & 1.0 & 0 & 0 & 0.95 & I \\
2 & 2 & 330 & 80 & 2.1 & 0.99 & 0 & 0 & 1.92 & I \\
3 & 3 & 330 & 50 & 2.0 & 0.80 & +5 & +400 & 3.22 & II/III \\
4 & 3 & 400 & 50 & 2.2 & 0.96 & +29 & +480 & 3.95 & I/II \\
5 & 3 & 405 & 35 & 3.5 & 0.93 & +20 & +480 & 7.24 & III \\
\hline 6 & 3 & 330 & 35 & 3.0 & 0.78 & +5 & +400 & 5.53 & III \\
7 & $3 L^{* *}$ & 530 & 20 & 7.2 & 0.97 & $>202$ & $>520$ & 23.74 & III/IV \\
8 & $3 \mathrm{~L}$ & 449 & 20 & 6.0 & 0.82 & +202 & +520 & 18.10 & III/IV \\
9 & 3 & 125 & 20 & 3.5 & 0.3 & -86 & +160 & 3.6 & III/IV \\
10 & $3 \mathrm{~L}$ & 330 & 20 & 4.8 & 0.65 & +135 & +360 & 12.07 & III/IV \\
\hline 11 & 2 & 330 & 35 & 6.5 & 0.91 & +132 & 0 & 9.21 & III \\
12 & 3 & 340 & 50 & 2.0 & 0.82 & +8 & +360 & 3.28 & II/III \\
13 & 3 & 370 & 35 & 3.3 & 0.85 & +19 & +440 & 6.62 & III \\
14 & $3 \mathrm{~L}$ & 430 & 20 & 5.8 & 0.82 & +171 & +480 & 17.18 & III/IV \\
15 & 3 & 330 & 93 & 1.0 & 0.83 & +5 & +400 & 0.53 & II \\
\hline 16 & 2 & 200 & 45 & 3.5 & 0.59 & -54 & -200 & 4.06 & III \\
17 & 3 & 250 & 45 & 1.8 & 0.64 & -27 & +280 & 2.66 & III \\
18 & 3 & 200 & 35 & 2.1 & 0.52 & -48 & +240 & 2.80 & III \\
19 & $3 \mathrm{~L}$ & 260 & 35 & 1.8 & 0.54 & -21 & +280 & 3.64 & III \\
\hline
\end{tabular}

* TPC $=$ Total Plant Cost, and OC $=$ Operating Cost Over 40 Years.

\# 14 cycles per year are assumed.

$* * 3 \mathrm{~L}=108 \mathrm{~L} 3$ element core; all other 3 element cores are $82.6 \mathrm{~L}$.

+ Unirradiated material. 
Table 5.2 - Relative Peak Thermal Neutron Flux for Various Enrichments and Core Sizes

\begin{tabular}{|c|c|c|c|}
\hline \multirow{2}{*}{ Enrichment } & \multicolumn{3}{|c|}{ Core Size } \\
\cline { 2 - 4 } & 2 Element & 3 Element (82.6 L) & 3 Element (108 L) \\
\hline 93 & 1.00 & - & - \\
\hline 80 & 0.99 & - & - \\
\hline 50 & - & 0.80 & - \\
\hline 35 & 0.91 & 0.78 & - \\
\hline 20 & - & - & 0.65 \\
\hline
\end{tabular}

The variation of required fuel density to generate $330 \mathrm{MW}$ and satisfy the 17-day cycle is shown in Table 5.3.

Table 5.3 - Fuel Density as a Function of Enrichment for Constant Power and Cycle Length

\begin{tabular}{|c|c|c|c|}
\hline \multirow{2}{*}{ Enrichment } & \multicolumn{3}{|c|}{ Core Size } \\
\cline { 2 - 4 } & 2 Element & 3 Element (82.6 L) & 3 Element (108 L) \\
\hline 93 & 1.7 & - & - \\
\hline 80 & 2.1 & - & - \\
\hline 50 & - & 2.0 & - \\
\hline 35 & 6.5 & 3.0 & - \\
\hline 20 & - & - & 4.8 \\
\hline
\end{tabular}

Thus, for constant power and cycle time, as the enrichment decreases the fuel density increases. The probability of fuel densities much above $3.5 \mathrm{gU} / \mathrm{cc}$ being successfully developed is low. 
When the findings of the fuel panel, outlined in chapter 4 , are included in this discussion, the following conclusions are implied:

1. The fuel density for cases $7,8,10,11$, and 14 is too high to be developed in a reasonable time, at a reasonable cost, and with an acceptable assurance of success.

2. The fuel density required for cases 5,9 , and 16 implies that these cores are marginally acceptable.

3. Only cases $1,2,3,4,12,15,17,18$, and 19 and, to a lesser extent, cases 6 and 13 are acceptable by the standards used by the fuel panel.

\section{$5.2 \operatorname{COST}$}

In the cost analysis, both the total plant cost (TPC) and operating cost (OC) were estimated. The comparative costs are expressed as differences from the base case design. All costs are expressed in fiscal year 1992 \$M.

Table 5.4 - Cost Changes as a Function of Enrichment for Constant Power and Cycle Length in FY $1992 \$ M$

\begin{tabular}{|c|c|c|c|}
\hline \multirow{2}{*}{ Enrichment } & \multicolumn{3}{|c|}{ Core Size } \\
\cline { 2 - 4 } & 2 Element & 3 Element (82.6 L) & 3 Element (108 L) \\
\hline 93 & $0,0^{*}$ &,-- &,-- \\
\hline 80 & 0,0 &,-- &,-- \\
\hline 50 &,,--- &,-- \\
\hline 35 & $+132,0$ & $+5,+400$ & $+135,+360$ \\
\hline 20 &,-- & $+5,+400$ &,-- \\
\hline
\end{tabular}

* The first value refers to TPC, the second value refers to OP.

Therefore, for constant power (330 MW) and cycle length, all cost estimates increase compared to the baseline design, regardless of the core's size and enrichment; further, the overall costs are dominated by operating costs. The increases tend to be largest for the lowest enrichments. Changing the power and/or the cycle time has the following cost implications: 
1. Lowering the operating power and changing the core design reduces the (case 9) TPC by $\$ 86 \mathrm{M}$ and increases the OC by $\$ 160 \mathrm{M}$.

2. For the cases considered, large cores operating at constant power ( $330 \mathrm{MW})$ have higher TPCs and OCs (case 10). This result also is true of the intermediate core size (cases 3 and 6).

3. Large and intermediate sized cores operating at higher power are uniformly more costly (cases 4,5 , and 8 , respectively).

4. The total plant costs for cases 8,10 , and 11 which require high density fuel results in an increased cost due to the additional fuel development effort.

The cost estimates are given in Appendix 22, and this analysis is reviewed in Appendix 23. The review concludes that the costs were underestimated (as were the implied time delays) of design changes from the baseline case, and that this difference could be significant.

\subsection{SAFETY CONSIDERATIONS}

A comprehensive safety analysis is beyond the scope of this study. Here, we indicate safety trends based on the parameters that were varied in this study. A full safety evaluation of any ANS design will require a detailed safety test and analysis program, which is currently planned by the ANS Project Office.

The safety implications of using LEU/MEU as the fuel for the ANS impact two areas. First, the higher fertile content will enhance the Doppler coefficient. However, as a result of the higher fertile content, more plutonium will be produced, which might affect the kinetic parameters of the core. Second, lower enrichments imply higher fuel densities, and this will reduce the thermal conductivity of the fuel plate. At similar power densities, the lower conductivities will result in higher temperatures at the plate's centerline, which will reduce the safety margins of the core. Finally, the larger cores required by the LEU cases have the following two safety-related characteristics:

1. At similar total powers, the larger volume cores will operate at lower power densities than smaller ones. However, since the centerline temperature is directly proportional to the power density, and inversely proportional to the thermal conductivity, a reduction in centerline temperature is not always implied. 
2. For the three-element design, the larger cores have large radial dimensions for the largest element (compare Figures 3.2 and 3.3), and correspondingly a lower curvature. Potentially, these plates are mechanically unstable at operating conditions, particularly if the centerline temperature increases.

The source term used in severe accident analysis would be affected by the increase in the inventory of higher actinides for those cores (lower enrichment). However, the impact of this change would have to be assessed. ANL studies of MTR reactors have shown that the presence of plutonium in LEU spent fuel, even with high burn-up, does not alter the radiological consequences resulting from hypothetical accidents.

Doppler coefficients were estimated for three cores of varying enrichment, at BOC. These results are given below.

Table 5.5 - Variation of Doppler Coefficient with Enrichment

\begin{tabular}{|c|c|}
\hline Enrichment & Doppler Coefficient $(\Delta \mathbf{k} / \mathbf{k} / \mathbf{K})$ \\
\hline 93 & $-1.49(-5)$ \\
\hline 50 & $-2.90(-5)$ \\
\hline 35 & $-5.80(-5)$ \\
\hline
\end{tabular}

Thus, there is an increase in the magnitude of the Doppler coefficient with decreasing enrichment.

The other safety implications have not been quantified yet. However, if one or more of the cores is selected for further study, all of them must be addressed in detail.

In terms of the power density and thermal margins of the cores, case 9 is by far the most attractive at $1.5 \mathrm{MW} / \mathrm{L}$, followed by cases $6,10,12,14,15,16,17,18$, and 19 with power density in the range of $2 \mathrm{MW} / \mathrm{L}$ and $4 \mathrm{MW} / \mathrm{L}$. All other cases are at, or near, the upper limit of power density (Table 3.4).

Finally, the impact of enrichment on the safety of an ANS-type core can be quantified by considering the following factors. The ratio of flux to power has been found to decrease with decreasing enrichment. Thus, any flux level achieved with less than fully enriched fuel could be achieved at a lower power in a similar core containing more highly enriched fuel. Therefore, thermal safety margins are potentially larger with higher enrichment fuel at the same flux performance level. 


\subsection{SAFEGUARDS CONSIDERATIONS}

This study did not address the international policy issues associated with non-proliferation. However, the safeguards parameters reported here provide a measure of the significance of designs with various enrichments and may be useful in formulating international policy options.

Table 5.6 evaluates the implications of various reactors on a U.S. domestic safeguards program that would be implemented by DOE. The DOE Safeguards Categories for unirradiated fuel are summarized in Table 5.1, together with the cumulative plutonium production per year.

In Table 5.6, Split Attractiveness Levels or Categories show whether the enrichment is at or just above the level given. Thus, the indicated cases could be lowered to the less significant Attractiveness Level and Category by a slight reduction in enrichment.

Categories are determined by Attractiveness Level and Quantity. Appendix 24 contains Table I-2 from DOE Order 5633.3A, "Control and Accountability of Nuclear Materials, " which was used to make the determinations shown in the table.

Safeguards requirements are determined by the Category. Requirements for Categories I and II include MC\&A planning and management, threat considerations, performance criteria, accounting system, physical inventories, measurement control, control limits, loss detection elements, training, access controls, containment, and surveillance. For Categories III and IV, requirements are determined by the local DOE Field Office and are less stringent. DOE Order 5633.3A is the basic document giving the requirements for the above safeguards measures. Appendix 24 also contains pages from this Order which show some differences dependent on Category. These were selected only because of their compactness; many more of the requirements fill the pages of the Order. In virtually all cases, the differences between Categories I and II are small (with respect to the effort and cost of following the requirements), while the requirements for Categories III and IV are less obtrusive, but the cost of following them may not be much less than meeting the requirements for Categories I or II.

We have estimated the number of equivalent cores that would have to be diverted to achieve a prompt critical assembly intended for non-peaceful purposes. This estimate was based on determining the critical mass for bare uranium spheres of various enrichments using the MCNP Monte Carlo code and its associated neutron cross-section library. Figure 5.1 gives the results of these calculations which show that there is a significant increase in critical mass for enrichments below 20\%. Thus, for example, the base case requires at least 2 equivalent cores, case 6 requires 7 equivalent cores, and case 9 requires 13 equivalent cores. 
Table 5.6 - Safeguards Considerations

\begin{tabular}{|c|c|c|c|c|c|c|c|c|}
\hline \multirow{2}{*}{ No. } & \multirow{2}{*}{$\begin{array}{c}\text { Enrichment } \\
(\%)\end{array}$} & \multirow{2}{*}{$\begin{array}{c}\text { Core } \\
\text { Volume } \\
\text { (L) }\end{array}$} & \multirow{2}{*}{$\begin{array}{c}\text { Total } \\
\text { Mass of } \\
\text { Uranium } \\
\text { (kg) }\end{array}$} & \multirow{2}{*}{$\begin{array}{c}\text { Contained } \\
\text { U-235 } \\
\text { (kg) }\end{array}$} & \multirow{2}{*}{$\begin{array}{c}\text { Attract. } \\
\text { Level } \\
\text { (Unirradiated) }\end{array}$} & \multicolumn{3}{|c|}{ Category for Full Core } \\
\hline & & & & & & Unirradiated & $\begin{array}{c}\text { 100R } 9 \\
1 \mathrm{M}\end{array}$ & $\begin{array}{c}15 R \\
1 \mathrm{M}\end{array}$ \\
\hline 1 & 93 & 67.6 & 25.4 & 23.6 & C & I & \multirow{19}{*}{$\begin{array}{c}\text { All } \\
\text { Attract. } \\
\text { Level } \\
\text { E, } \\
\text { Category } \\
\text { IV }\end{array}$} & III (D) \\
\hline 2 & 80 & 67.6 & 31.4 & 25.1 & c & I & & III (D) \\
\hline 3 & 50 & 82.6 & 39.0 & 19.5 & $\mathrm{C} / \mathrm{D}$ & II/III & & III (D) \\
\hline 4 & 50 & 82.6 & 42.8 & 21.4 & C/D & I/III & & III (D) \\
\hline 5 & 35 & 82.6 & 68.1 & 23.8 & D & III & & III (D) \\
\hline 6 & 35 & 82.6 & 58.3 & 20.4 & D & III & & III (D) \\
\hline 7 & 20 & 108 & 193.6 & 38.7 & $\mathrm{D} / \mathrm{E}$ & III/IV & & III/IV \\
\hline 8 & 20 & 108 & 161.1 & 32.2 & $\mathrm{D} / \mathrm{E}$ & III/IV & & III/IV \\
\hline 9 & 20 & 82.6 & 68.0 & 13.6 & $\mathrm{D} / \mathrm{E}$ & III/TV & & III/IV \\
\hline 10 & 20 & 108 & 129.0 & 25.8 & $\mathrm{D} / \mathrm{E}$ & III/IV & & III/IV \\
\hline 11 & 35 & 67.6 & 97.1 & 34.0 & D & III & & III (D) \\
\hline 12 & 50 & 82.6 & 39.0 & 19.5 & $\mathrm{C} / \mathrm{D}$ & IIIIII & & III (D) \\
\hline 13 & 35 & 82.6 & 64.3 & 22.5 & $\mathrm{D}$ & III & & III (D) \\
\hline 14 & 20 & 108 & 156.0 & 31.2 & $\mathrm{D} / \mathrm{E}$ & III/TV & & III/V \\
\hline 15 & 93 & 82.6 & 18.5 & 17.2 & c & II & & II (D) \\
\hline 16 & 45 & 67.6 & 52.2 & 23.5 & D & III & & III (D) \\
\hline 17 & 45 & 82.6 & 35.1 & 15.8 & D & III & & III (D) \\
\hline 18 & 35 & 82.6 & 40.9 & 14.3 & D & III & & III (D) \\
\hline 19 & 35 & 108 & 48.4 & 16.9 & D & III & & III (D) \\
\hline
\end{tabular}




\subsection{MULTI-ATTRIBUTE RATING METHODS}

The multi-attribute method is an approximate way of rating the nineteen configurations for which all relevant data were available; such attributes are relative flux, overall cost, power density, fuel density, core volume, and safeguards. Power density and fuel density both represent safety, and core volume together with fuel density represents technical feasibility. The cost of a domestic safeguards program is not explicitly represented, and the overall cost accounts for total project costs (including a fuel development program) and operating costs.

Relative Flux: The ten cases have been binned into four ratings with 1 the most and 4 the least desirable. Rating 1 includes cases with flux $\geq 95 \%$, Rating 2 includes cases with fluxes $75-95 \%$, Rating 3 is $65-75 \%$, and Rating 4 is below $65 \%$.

Cost: Similar to the above, Rating 1 represents no increase over the base case, Rating 2 is $\sim+\$ 0.1 \mathrm{~B}$, Rating 3 is $\sim+\$ 0.1-+0.5 \mathrm{~B}$, and Rating 4 is $z+\$ 0.5 \mathrm{~B}$.

Power Density (MW/L): Rating 1 is $1.5-3.0$, Rating 2 is 3.0-4.0, Rating 3 is 4.0-4.5, and Rating 4 is $\geq 4.5$.

Fuel Density (gU/ce): Rating 1 is $1.7-2.2$, Rating 2 is 2.2-3.5, Rating 3 is 3.5-6.0, and Rating 4 is $\geq 6.0$.

Core Volume: There are only three ratings, $1,2,3$, which correspond to the three core volumes.

Safeguards: Rating 1 is Category III/IV, Rating 2 is Category III, Rating 3 is Category II/III and I/III, and Rating 4 is Category I/II. International policy concerns related to nonproliferation arguably are a monotonic function of safeguards category.

Table 5.7 shows the results of applying this method to the nineteen cases. 
Table 5.7 - Multi-attribute Rating of Nineteen Reactor Configurations

\begin{tabular}{|c|c|c|c|c|c|c|}
\hline Case & $\begin{array}{c}\text { Relative } \\
\text { Flux }\end{array}$ & Cost & $\begin{array}{c}\text { Power } \\
\text { Density }\end{array}$ & $\begin{array}{c}\text { Fuel } \\
\text { Density }\end{array}$ & $\begin{array}{c}\text { Core } \\
\text { Volume }\end{array}$ & Safeguards \\
\hline 1 & 1 & 1 & 4 & 1 & 1 & 4 \\
\hline 2 & 1 & 1 & 4 & 1 & 1 & 4 \\
\hline 3 & 2 & 3 & 3 & 1 & 2 & 3 \\
\hline 4 & 1 & 3 & 4 & 1 & 2 & 3 \\
\hline 5 & 2 & 3 & 4 & 2 & 2 & 2 \\
\hline 6 & 2 & 3 & 3 & 2 & 2 & 2 \\
\hline 7 & 1 & 4 & 4 & 4 & 3 & 1 \\
\hline 8 & 2 & 4 & 3 & 4 & 3 & 1 \\
\hline 9 & 4 & 2 & 1 & 2 & 2 & 1 \\
\hline 10 & 3 & 3 & 2 & 3 & 3 & 1 \\
\hline 11 & 2 & 2 & 4 & 4 & 1 & 2 \\
\hline 12 & 2 & 3 & 3 & 1 & 2 & 3 \\
\hline 13 & 2 & 3 & 3 & 2 & 2 & 2 \\
\hline 14 & 2 & 4 & 2 & 3 & 3 & 1 \\
\hline 15 & 2 & 3 & 3 & 1 & 2 & 4 \\
\hline 16 & 4 & 1 & 1 & 2 & 1 & 2 \\
\hline 17 & 4 & 3 & 2 & 1 & 2 & 2 \\
\hline 18 & 4 & 3 & 1 & 1 & 2 & 2 \\
\hline 19 & 4 & 3 & 1 & 1 & 3 & 2 \\
\hline & & & & & & \\
\hline
\end{tabular}


Based on this simplified compendium of the nineteen cases, the following observations can be made:

1. No case is superior on all attributes.

2. Cases 1 and 2 trade flux with power density and safeguards in Case 9; Case 9 is slightly inferior to Cases 1 and 2 on other attributes.

3. Cases 5 and 6 are equal on all attributes but trade flux and power density.

4. Except for flux, Case 8 is inferior to Case 10.

5. Cases 3 and 4 trade flux with power density.

6. Cases 16-19 are attractive with regard to fuel density, power density, and safeguards, but are less attractive for flux and cost.

In using Table 5.7 to obtain an overall figure of merit for each case, a decision maker may want to assign weighting factors to each attribute and then combine the scores to obtain a single rating for each case. 


\section{Variation of Critical Mass of Bare Uranium Spheres with Enrichment}

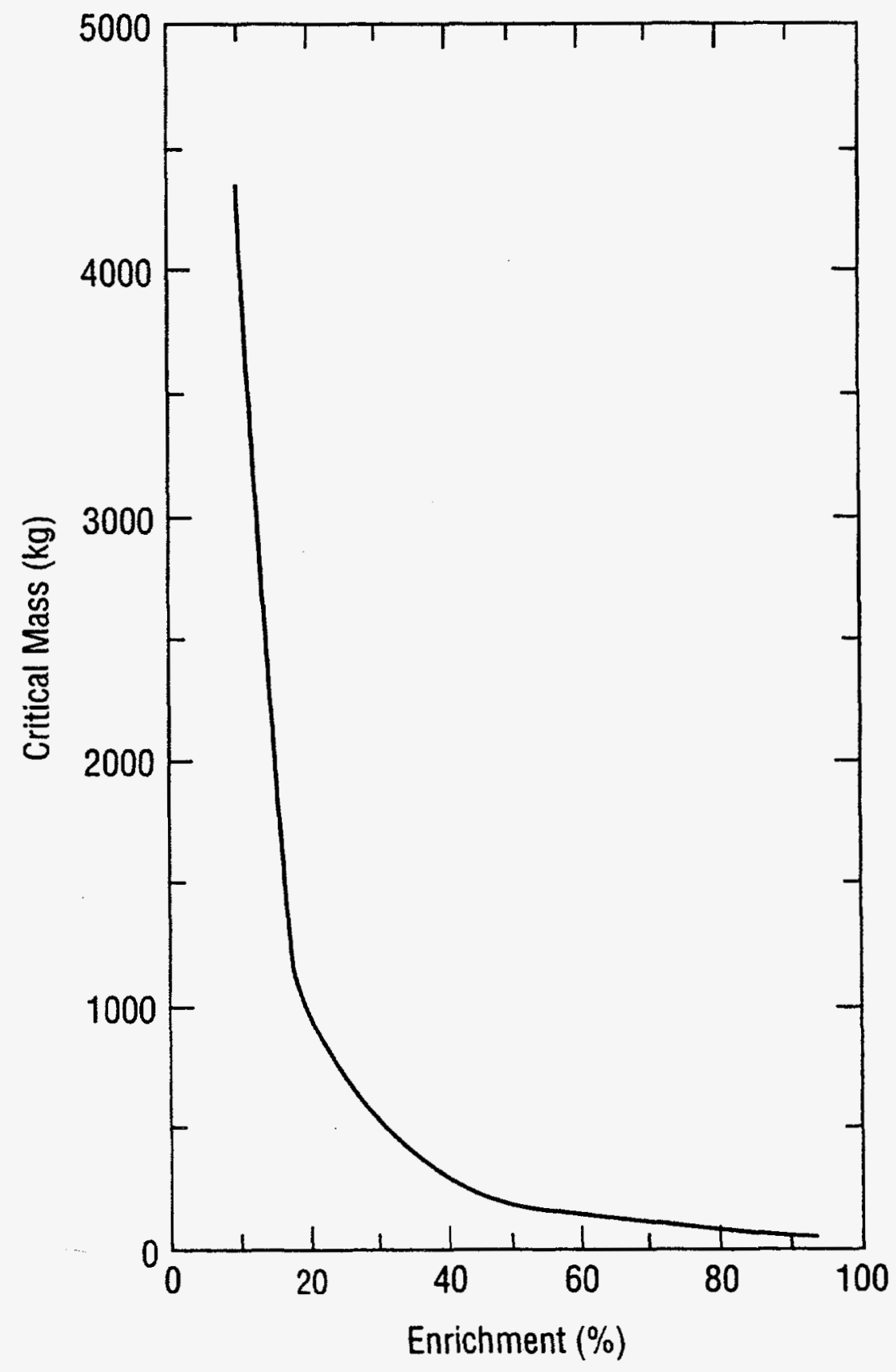

Figure 5.1 Variation of the Critical Mass of Bare Uranium Spheres with Enrichment 


\subsection{CONCLUSIONS}

\subsection{COMPLETENESS OF STUDY}

The search for reduced enrichment designs that may compare favorably with the flux performance of the existing design is an inductive process. To assure ourselves that all reasonable combinations of enrichment, core volume, fuel density, and power were investigated, an event tree format was used, as described below.

For each of the core sizes considered $(67.6 \mathrm{~L}, 82.6 \mathrm{~L}$, and $108 \mathrm{~L}$ ), an event tree was constructed which had enrichment, fuel density, and total power as top events. Three enrichment ranges were considered, approximately corresponding to HEU, MEU, and LEU fuel. Two fuel density ranges were included, corresponding to extremely likely of success $(1.7 \mathrm{gU} / \mathrm{cc}-3.5 \mathrm{gU} / \mathrm{cc})$ and the other less likely of success $(3.5 \mathrm{gU} / \mathrm{cc}-6.0 \mathrm{gU} / \mathrm{cc})$. Finally, three power levels of interest to the ANS are considered. These combinations allow a maximum of 15 different core configurations for each volume. In the case of the smallest core being considered, only two enrichment ranges were used, since within the fuel density constraints the LEU cases would probably not be critical for the 17-day cycle. The results of these event trees are shown on Figures 6.1 through 6.3 and, where possible, the case numbers are shown.

Figure 6.1 shows the tree for the smallest core with comments on the right-hand side. The following general comments can be made:

1. In all cases, for total powers levels above $330 \mathrm{MW}$, the power density will be unacceptably high.

2. Cases with a fuel density above $3.5 \mathrm{gU} / \mathrm{cc}$ have a lower probability of success and may encounter thermal problems for extremely high densities.

Figure 6.2 shows the tree for the $82.6 \mathrm{~L}$ three-element core with comments. The total power limit is $405 \mathrm{MW}$; thus, the upper branch on power level is acceptable. Furthermore, the same concern about fuel density applies to this core as well as to the small core.

Figure 6.3 shows the tree for the largest core considered. Here, the entire design raises concerns about possible flow-induced plate instabilities. These instabilities arise from the fact that for the core, the outermost element is composed of plates with a low curvature which are not as stiff as those of the inner elements. The same fuel density concerns expressed above also apply to these cores. We note that there is a significant cost penalty associated with the larger cores compared to the baseline core at an equal performance level.

These event tree outcomes show that all reasonable cases have been included in this study. Furthermore, J. Ryskamp, Idaho National Engineering Laboratory noted that the reactor design of the ANS began in 1985 with pre-conceptual studies performed mainly at INEL and ORNL. Over the past nine years, these laboratories and others have studied nearly every aspect of ultra- 
high-flux reactor design. These studies examined different fuel enrichments, fuel types $\left(\mathrm{U}_{3} \mathrm{Si}_{2}\right.$, $\mathrm{UAl}_{x}, \mathrm{U}_{3} \mathrm{O}_{8}$ ), fuel-plate shapes (involute, arcuate, concentric), core geometries (axially split, radially split, two to several fuel elements), coolants $\left(\mathrm{D}_{2} \mathrm{O}, \mathrm{H}_{2} \mathrm{O}, \mathrm{D}_{2} \mathrm{O} / \mathrm{H}_{2} \mathrm{O}\right.$ mixtures), moderators $\left(\mathrm{D}_{2} \mathrm{O}, \mathrm{H}_{2} \mathrm{O}, \mathrm{Be}\right)$, control systems, and many other features. During this effort (costing tens of millions of dollars), the reactor design evolved to one that is near optimum within the various constraints and requirements, such as reactor performance, safety, cost, and development risk.

Adding a new requirement for reactor safeguards, such as requiring the fuel to contain $20 \%$ enriched uranium, certainly will force a redesign toward some new optimum. However, based on a wealth of experience, a new reactor design with LEU would not look significantly different from the current design (for example, it would not consist of fuel rods in graphite). Therefore, the enrichment trade-off studies reported here provide a reasonably complete set of designs from which enrichment decisions can be made.

In conclusion, none of the four laboratories could identify any logical gaps in our mutual approach to the study. No major flaws or even suspected flaws were identified or even suggested at the review meeting of the principal participants from the four laboratories at Brookhaven on January 21, 1994. (See Appendix 25)

\subsection{SUMMARY OF MAIN FINDINGS}

The existing (or reference) reactor design contains $93 \%$ enriched uranium, a fuel density of 1.7 gU/cc and operates at 330 megawatts. Based on the many configurations evaluated, the following main conclusions are drawn.

1. HEU is better than lower enriched uranium fuels for the flux performance of the Advanced Neutron Source; in particular, MEU and LEU configurations consistently led to an inferior flux performance.

2. If the enrichment were reduced to 35\% (MEU), then a reactor configuration was identified which meets the above criteria (Section 2). In this reactor, the core volume would be increased to $82.6 \mathrm{~L}$, the fuel density would be increased to $3 \mathrm{gU} / \mathrm{cc}$, the power would remain at 330 megawatts, but the resulting neutron flux would be approximately $20 \%$ less than in the existing design. The additional cost of the project, above the current cost of the existing design ( $\$ 2.7 \mathrm{~B}$ ), would be approximately $\$ 0.4$ billion, mostly due to an increase in operating costs over the lifetime of the plant. Only $\$ 5 \mathrm{M}$ additional would be needed for total project costs. The uranium mass of the core would be approximately $60 \mathrm{~kg}$, and from a safeguards perspective, 7 full cores would be required to achieve a prompt critical system.

3. If the enrichment were reduced to $20 \%$, then a reactor could be designed within the confines of the technology for the reference plant. The core volume would be increased to $82.6 \mathrm{~L}$, the fuel density would be increased to $3.5 \mathrm{gU} / \mathrm{cc}$ (the practical upper limit), the power would have to be decreased to 125 megawatts, and the resulting neutron flux would be approximately $70 \%$ less than in the existing design. The additional cost of the 
project would be approximately $\$ 90$ million, resulting from a $\$ 160 \mathrm{M}$ increase in operating costs over the plant's lifetime relative to the reference plant but a $\$ 70 \mathrm{M}$ decrease in total project costs because this reactor would operate at a much lower power. At this enrichment, more than 13 full cores would be needed to achieve a prompt critical system.

These main conclusions are given for configurations that have the best technical chance of succeeding for the stated enrichments and with the derived flux and cost penalties. For MEU fuel, other reactors can be designed for which the flux penalty relative to the existing design would be approximately $10 \%$. This can be achieved by increasing the power in the MEU case, described in item 2 , to 405 megawatts, the maximum permissible based on heat-removal considerations, and increasing the fuel density to $3.5 \mathrm{gU} / \mathrm{cc}$. The additional cost of this design is $\$ 0.5 \mathrm{~B}$, relative to the reference design. A high flux also can be achieved with MEU by increasing the fuel density to $6.5 \mathrm{gU} / \mathrm{cc}$ in the reference core volume with power at 330 megawatts. However, the Fuel Experts Panel concluded that a program to develop fuel with density $6.5 \mathrm{gU} / \mathrm{cc}$ has more than a $90 \%$ chance of failure.

For LEU fuel, reactors can be designed with a less severe flux penalty than described in item 3 . Thus, a reactor can be designed with LEU that has a $35 \%$ flux penalty relative to the reference design, would operate at 330 megawatts in the largest core volume, $108 \mathrm{~L}$, and requires a fuel density of $4.8 \mathrm{gU} / \mathrm{cc}$. Again, the Fuel Experts Panel judged that development of fuel for the Advanced Neutron Source at this density is likely to fail. Higher fluxes can be achieved by increasing the power in this core to 430 megawatts and increasing the fuel density to $5.8 \mathrm{gU} / \mathrm{cc}$. This implies a flux penalty of approximately $20 \%$. In addition, a research and development program would be needed to assess the technical feasibility of the $108 \mathrm{~L}$ core.

The Study Group also evaluated the impact of reducing the enrichment of the fuel to $80 \%, 50 \%$, and to $45 \%$. No significant differences were found in performance, cost, technical feasibility, or safety for the first case. Two full cores (4 elements) would be needed to achieve a prompt critical system. For $50 \%$ enrichment, the flux penalty could be limited to $10 \%$ provided that the power is increased to 400 megawatts in the $82.6 \mathrm{~L}$ core. The fuel density would be increased to the reasonably achievable value of $2.2 \mathrm{gU} / \mathrm{cc}$, but the additional operating costs would be $\$ 0.5$ billion over the life of the facility. About 4 cores would be needed to achieve a prompt critical system. The $45 \%$ enrichment cases were lower power density studies in the $67.6 \mathrm{~L}$ and $82.6 \mathrm{~L}$ core volumes. Both led to approximately $40 \%$ flux penalties with fuel densities that do not exceed $3.5 \mathrm{gU} / \mathrm{cc}$.

In summary, the Enrichment Study Group found that although it would be feasible to redesign the Advanced Neutron Source to operate with MEU or LEU fuels, such designs would significantly reduce performance and increase cost. Other designs, which have the potential to maintain performance, would incur significant additional costs, and moreover would have a high probability of technical failure. 


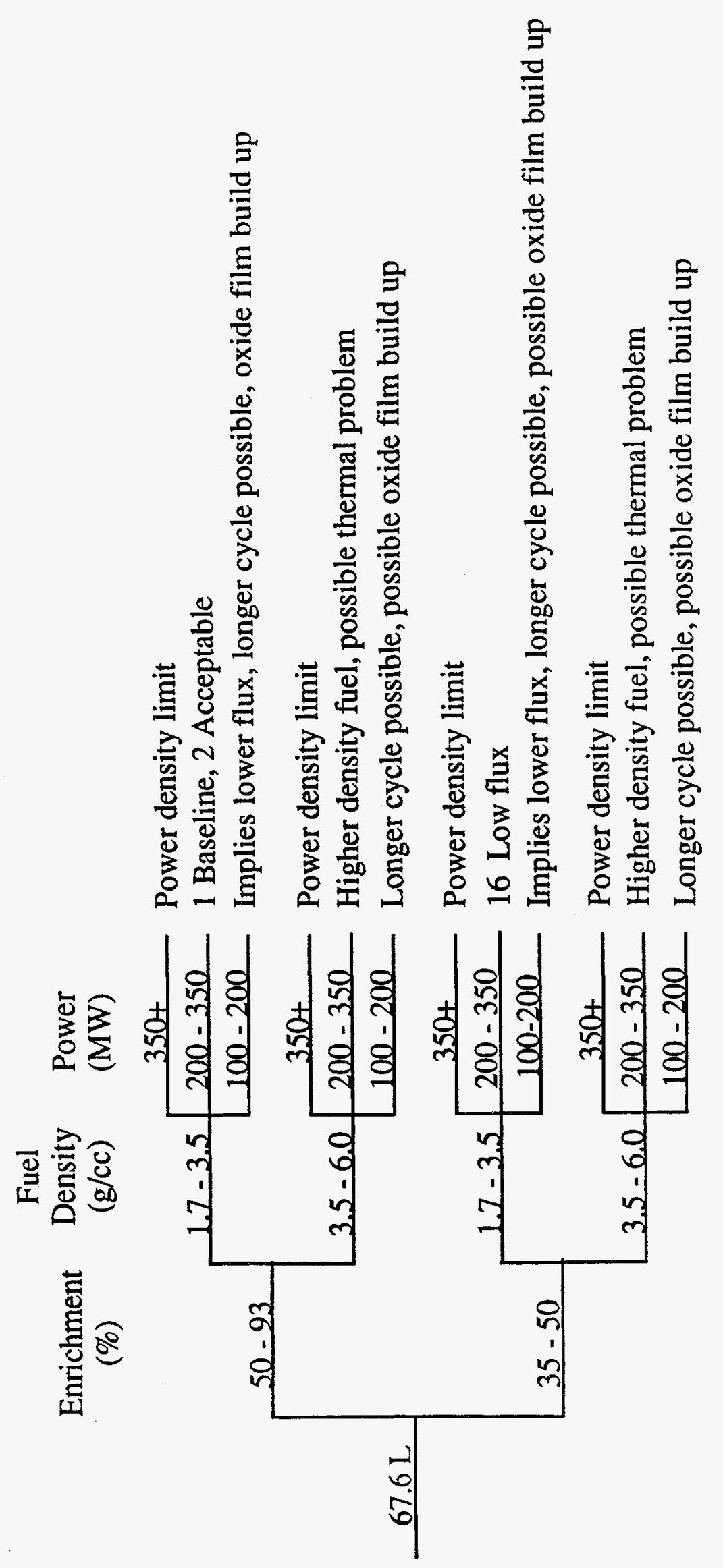

 


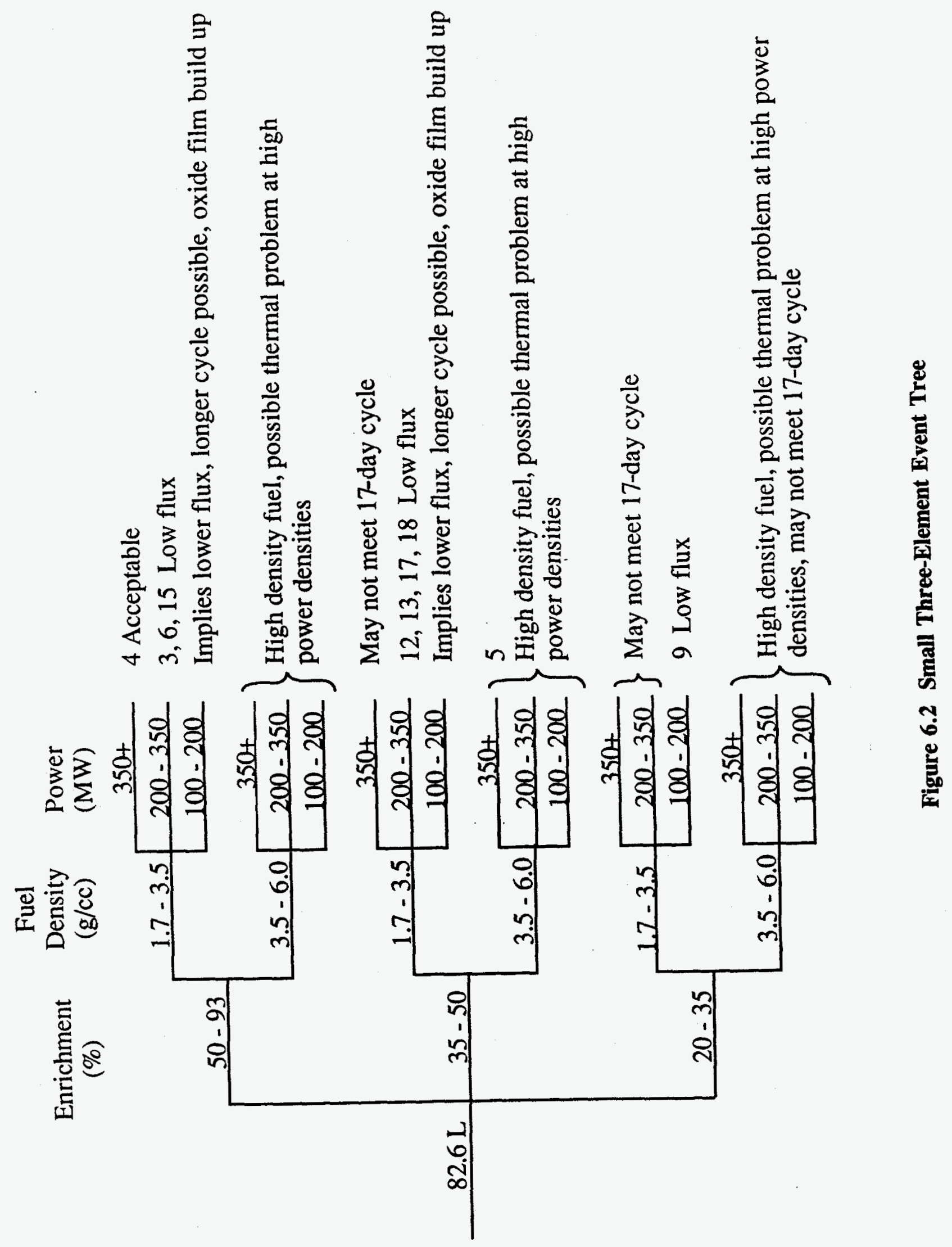




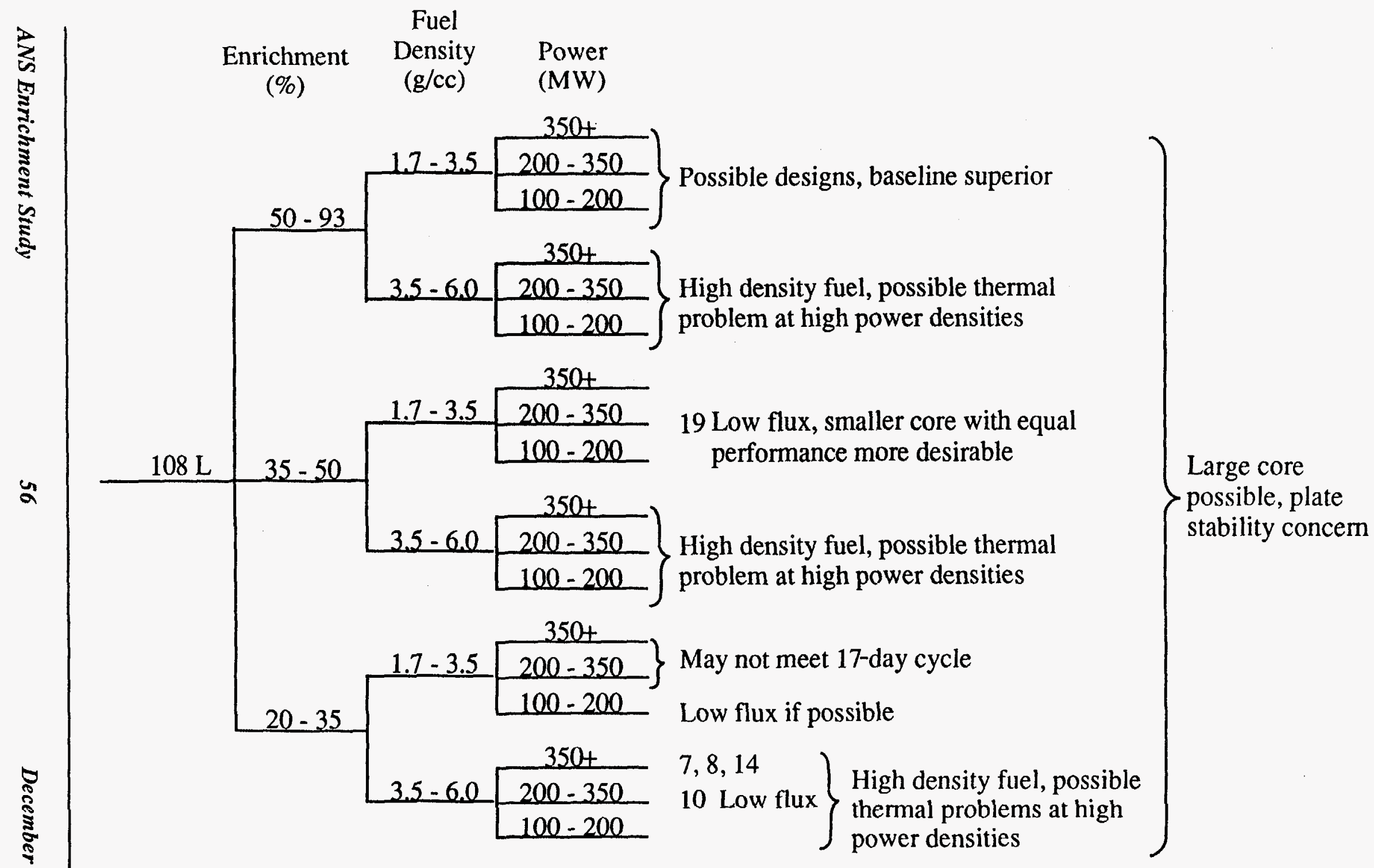

Figure 6.3 Large Three-Element Event Tree 